\title{
As dimensões espaciais da cadeia produtiva do leite em Minas Gerais
}

Spatial scopes of the milk production chain in Minas Gerais

\begin{abstract}
Minas Gerais is the largest national milk producer. Milk activity is an important generator of direct and indirect jobs, and its evaluation can contribute to a better understanding of the regional growth process. Thus, this paper evaluated the spatial dimension of the milk production chain in Minas Gerais. The supply side and the intermediate and final demand side treat these dimensions. In this way, we performed the mapping and the proposal of a typology of the municipalities in this productive chain through the construction of latent potential indicators. The main results allow tracing corridors, which can boost the economic development and the social insertion of the municipalities in this production chain. In addition, we identified that the production growth is spatially concentrated. Therefore, from this analysis, we provide subsidies for the formulation of investment policies and microcredit policies for this activity.
\end{abstract}

\section{Keywords}

factorial analysis; clusters analysis; spatial autoregressive model; regional productivity; municipalities typology of Minas Gerais.

JEL Codes R10; Q10; C38; C31.
Fernando Salgueiro Perobelli (1)

Inácio Fernandes de Araújo Junior (2)

Lucas Siqueira de Castro (3)

(1) Universidade Federal de Juiz de Fora

(2) Universidade Federal de Juiz de Fora

(3) Universidade Federal Rural do Rio de Janeiro

\section{Resumo}

Minas Gerais é o maior produtor nacional de leite. Essa atividade é uma importante geradora de empregos diretos e indiretos, e a sua avaliação pode contribuir para o melhor entendimento do processo de crescimento regional. Assim, este artigo avaliou as dimensões espaciais da cadeia produtiva do leite em Minas Gerais. Tais dimensões foram tratadas pelo lado da oferta e da demanda intermediária e final. Foram realizados o mapeamento e a proposta de uma tipologia dos municípios nessa cadeia produtiva por meio da construção de indicadores de potencial latente. Os principais resultados permitem traçar corredores, que podem impulsionar o desenvolvimento econômico e a inserção social dos municípios inseridos nessa cadeia produtiva. Além disso, identificamos que o crescimento da produção está ocorrendo de forma concentrada espacialmente. Portanto, por meio dessa análise fornecemos subsídios para que sejam formuladas politicas de atração de investimentos e de microcrédito para essa atividade.

\section{Palavras-chave}

análise fatorial; análise de clusters; modelo autoregressivo espacial; produtividade regional; tipologia dos municípios mineiros.

Códigos JEL R10; Q10; C38; C31. 


\section{Introdução}

A cadeia produtiva do leite, num contexto mundial, passa por um processo de acelerada modernização tecnológica no que se refere ao processo produtivo. Dentre as tendências mundiais é possível destacar que nos últimos anos houve: a) redução da quantidade total de vacas utilizadas para a produção de leite; b) aumento no tamanho individual das fazendas em área, em quantidade de vacas e em volume de produção; c) redução no número de fazendas produtoras de leite; d) melhoria do potencial genético do rebanho; e) aumento da produção na maior parte dos países produtores; e f) crescimento da oferta mundial e da qualidade da produção (Embrapa, 2011; Vilela et al. 2017).

No contexto nacional, o tamanho da fazenda ainda é pequeno quando comparado a outros países. Entretanto, as fazendas brasileiras estão crescendo em termos de volume individual de produção. Ademais, a sua inserção no mercado internacional está atrelada, em parte, à adaptação às mudanças tecnológicas e de mercado, especialmente em eficiência produtiva e qualidade da produção. Desta maneira, a trajetória tecnológica da agropecuária nos últimos anos tem passado por intensa adoção de tecnologias para aumento de produtividade e redução de danos ambientais (Souza; Lima, 2003; Perobelli et al., 2007; Almeida; Perobelli; Ferreira, 2008; Campos; Pereira; Teixeira, 2014).

Aliados às mudanças no contexto produtivo nacional e internacional, percebe-se um movimento de expansão da oferta de leite e aumento de sua qualidade, que estão relacionados ao crescimento da renda per capita e às mudanças de hábitos e conscientização dos consumidores. A importância desse setor tem despertado o interesse de diversos estudos que tiveram como foco identificar o padrão espacial da produção e a eficiência na cadeia produtiva, e.g., Lopes, Reis e Yamaguchi (2007), Hunt et al. (2009) e Siqueira, Kilmer e Campos (2010).

Minas Gerais é o estado brasileiro, atualmente, com maior produção de leite. Em 2015, foi responsável por 26,1\% da produção nacional. Ao avaliar a distribuição da produção por mesorregião é possível verificar certo grau de heterogeneidade espacial na mesma. As principais mesorregiões produtoras, no ano de 2015, foram: Triângulo Mineiro/Alto Paranaíba (26,3\%) e Sul/Sudoeste de Minas (15,9\%). Essa concentração produtiva está relacionada às características tecnológicas e de especialização regional em Minas Gerais (Lemos et al., 2003). 
Portanto, dentro desse contexto de modificações tanto em nível mundial quanto nacional e buscando compreender os determinantes do crescimento de produção dessa atividade, o presente artigo tem por objetivo avaliar as dimensões espaciais da cadeia produtiva do leite em Minas Gerais. Tal dimensão foi tratada tanto pelo lado da oferta quanto pelo lado da demanda, que nesse caso foi dividida entre demanda intermediária e demanda final. Desta forma, este estudo apresenta indicadores de potencial latente da atividade leiteira em nível municipal; proposta de tipologia de municípios para avaliar o potencial de formação de clusters com características de oferta e de demanda semelhantes; além de tratar as questões de heterogeneidade espacial no crescimento da produção de leite de forma explícita por meio de um modelo econométrico espacial.

A cadeia produtiva do leite é capaz de gerar impactos em diversos setores da economia, devido aos efeitos de encadeamento produtivo tanto na relação de aquisição de insumos quanto no fornecimento para as indústrias de beneficiamento (Montoya; Finamore, 2005). Logo, a atividade leiteira é uma importante geradora de empregos diretos e indiretos em toda a cadeia de produção. Portanto, a avaliação espacial dessa atividade pode contribuir positivamente para o melhor entendimento do processo de crescimento regional.

Este estudo está estruturado, além desta introdução, da seguinte forma. Na segunda seção são discutidos os aspectos relacionados à estrutura da cadeia produtiva do leite, tal como a especialização e distribuição espacial dessa atividade/cadeia produtiva em Minas Gerais. Na terceira seção é apresenta a abordagem metodológica, com a descrição do método da análise fatorial e da análise de clusters utilizados para identificar as diferentes dimensões da cadeia produtiva leiteira nos municípios mineiros. Nessa seção também é apresentado o modelo autoregressivo espacial com controle adicional para variáveis endógenas, utilizado para analisar os determinantes do crescimento da produção de leite em Minas Gerais. Na quarta seção é detalhada a base de dados usada no estudo. Na quinta seção, os resultados do estudo são discutidos. E, por fim, na sexta seção são apresentadas as principais conclusões e sugestões para a formulação de políticas. 


\section{Cadeia produtiva do leite}

O conceito de cadeia produtiva é amplamente estabelecido pela literatura (Davis; Goldberg, 1957; Araújo et al., 1990; Silva, 1991; Batalha, 1997; Azevedo, 2000; Castro, 2001). Em geral, trabalha-se com a ideia de que a cadeia produtiva atua como espécie de sistema, composto por uma ou mais empresas/indústrias ligadas a diferentes áreas do setor econômico. Neste sistema, estabelecem-se interações que convergem na realização de um processo produtivo, o qual compreende desde a captação de matérias primas (insumos) até a elaboração do produto/serviço final, normalmente orientado para a oferta no mercado ${ }^{1}$.

Direcionando o conceito ao campo agropecuário, pode-se então definir a cadeia de produção agroindustrial como o somatório das atividades (produção e comercialização) realizadas para oferecer um produto agroindustrial, quer seja in natura ou processado (Araújo et al., 1990). A compreensão destes conceitos pelos membros da cadeia é importante, pois permite gerenciar manutenções e atualizações ao longo do processo de produção em formas distintas (Silva, 2001). Visualizando a cadeia integralmente, os indivíduos são capazes de identificar seus pontos fracos e fortes. Ao mesmo tempo, também são capazes de motivar o estabelecimento de cooperação técnica, visando identificar possíveis gargalos, para assim aumentar sua competitividade em cada seguimento em que atuam.

Entre os variados tipos de cadeias agroindustriais, sabe-se que o direcionamento deste trabalho focará no comportamento especifico do leite brasileiro. Esta cadeia desempenha papel relevante no suprimento de alimentos e também na geração de emprego e renda à população, o que faz com que o país atue como um dos grandes players mundiais neste mercado. No ano de 2014, o Brasil ocupou a quarta posição entre os maiores produtores de leite (de vaca) no mundo, com um volume de 35,1 milhões toneladas, sendo responsável por 50,2\% de todo o leite produzido na América do Sul. Em termos de rebanho, o país ocupa a segunda colocação, com aproximadamente 23 milhões de cabeças de gado (FAO, 2017).

1 Caso a cadeia produtiva seja formada por uma única empresa, ou por um conglomerado que se comporta desta maneira, diz-se que esta realiza uma integração vertical das atividades. Em contrapartida, cadeias formadas por duas ou mais empresas, com razões sociais diferentes, realizam um tipo de integração denominada horizontal (Silva, 1991; Castro, 2001). 
A Figura 1 exibe os elos da produção leiteira no Brasil (Gomes; Leite, 2001; FBB, 2010). O primeiro elo pode ser tido como insumos, fatores para produção ou matérias primas. Neste elo são contemplados tantos insumos para o trato com o animal, bem como de maquinário para ordenha, resfriamento, armazenagem e distribuição do leite, dentre outros. O segundo elo compreende os produtores ou unidades de produção primária. O terceiro elo representa o papel da rede de distribuição e logística, muitas vezes realizados através de associações e cooperativas, em intermediar a distribuição do leite, ainda in natura, facilitando o acesso entre produtores e indústrias.

Figura 1 Representação simplificada da cadeia do leite no Brasil

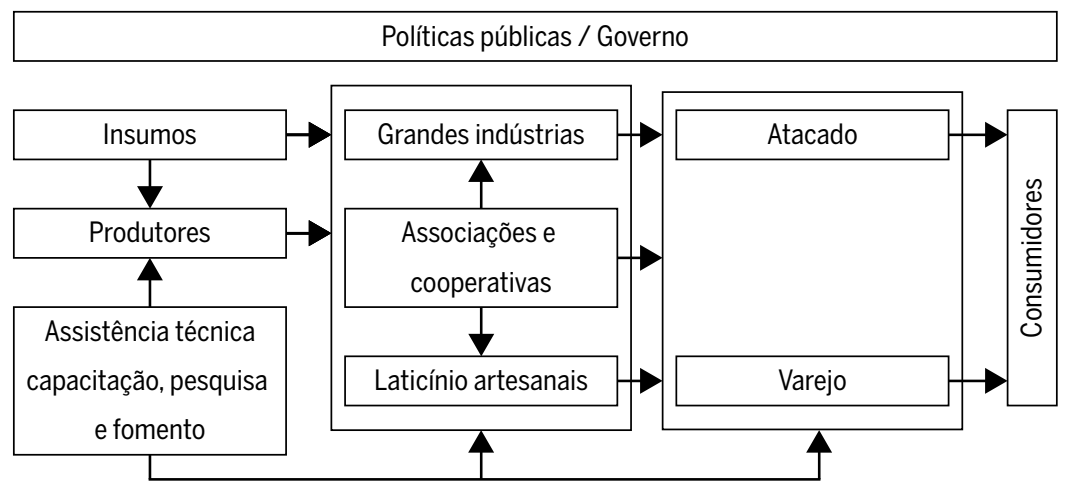

Fonte: Adaptada de Gomes e Leite (2001) e FBB (2010).

No que diz respeito ao quarto elo, o mesmo abrange estabelecimentos responsáveis pelo beneficiamento do leite, tais como, laticínios artesanais e grandes indústrias. $\bigcirc$ quinto elo reproduz o papel de instituições públicas e privadas em prol da assistência técnica, da capacitação, da pesquisa e do fomento no setor. Exemplos de empresas atuantes neste elo são dados por: Embrapa, Emater, Instituições Financeiras, Cooperativas, a Secretaria Especial de Agricultura Familiar e Desenvolvimento Agrário (antigo MDA), Ministério da Agricultura, Pecuária e Abastecimento (MAPA), dentre outros. Por último, tem-se o elo da participação dos centros de comercialização finais, aqui representado pelas redes de atacado e varejo. Nesse estágio da cadeia produtiva novamente a rede de logística é importante para garantir que o leite e seus derivados cheguem até os consumidores finais. 


\subsection{A pecuária leiteira em Minas Gerais}

A demanda por produtos lácteos no Brasil tem aumentado mais do que o crescimento da população (Vilela et al., 2017). O potencial de crescimento dessa atividade, associado aos encadeamentos setoriais ao longo da sua cadeia de produção, é capaz de impulsionar diversos setores produtivos (Montoya; Finamore, 2005). Nessa perspectiva, Martins e Guilhoto (2001) mostram o potencial da atividade leiteira para a geração de empregos, renda e arrecadação tributária na economia brasileira. Assim, essa atividade tem o potencial de influenciar o desenvolvimento regional (Viana; Ferras, 2007). Desse modo, o entendimento da evolução dessa atividade com as suas especificidades espaciais pode permitir a formulação de políticas que influenciem o processo de crescimento regional. A Figura 2 mostra a evolução na participação da produção de leite dos seis maiores Estados produtores brasileiros. No ano de 2015, Minas Gerais (26,1\%), Paraná (13,3\%), Rio Grande do Sul $(13,1 \%)$, Goiás (10,0\%), Santa Catarina (8,7\%) e São Paulo $(5,0 \%)$ foram responsáveis por cerca de $75,0 \%$ da produção nacional de leite.

Figura 2 Participação na produção de leite nacional: principais estados produtores

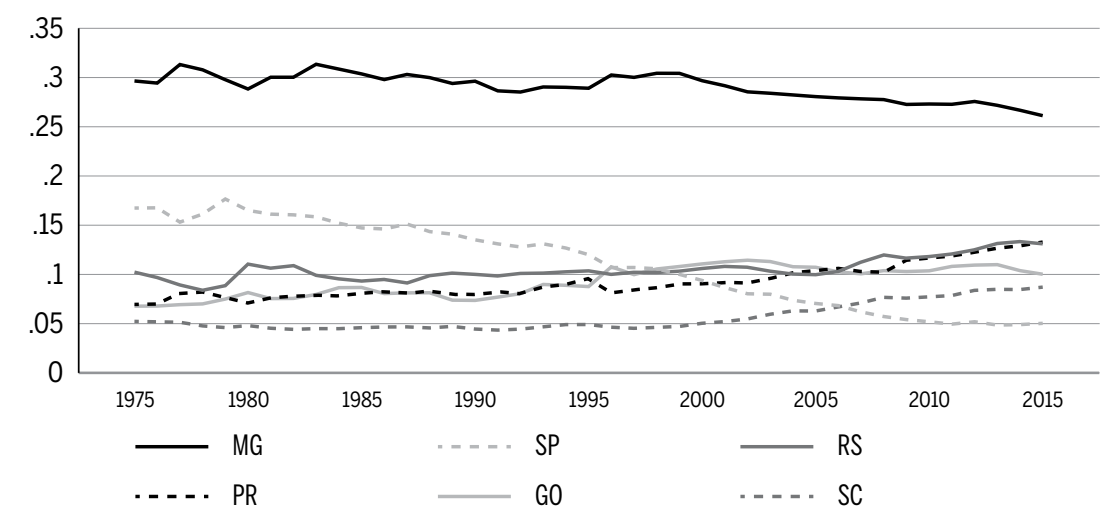

Fonte: Elaborada pelos autores, a partir de dados da PPM/IBGE.

Por sua vez, as Figuras 3, 4 e 5 contextualizam o panorama da produção leiteira em Minas Gerais. No ano de 2006, a produção de leite mineira, Figura 3, concentrou-se nas mesorregiões do Triângulo Mineiro/Alto Paranaíba (26,3\%) e do Sul/Sudoeste de Minas (15,9\%). Os menores níveis de produção estão nas mesorregiões do Jequitinhonha (1,7\%) e do Vale do Mucuri (2,3\%). 
De acordo com dados do Censo Agropecuário, o número de estabelecimentos que produzem leite caiu $25,9 \%$ entre $1996-2006$ e 20,1\% entre 2006-2014. No entanto, a produção de leite aumentou $87,0 \%$ no período entre 1996-2014 (Vilela et al. 2017). A evolução na produção foi justificada pelas mudanças técnicas nas propriedades rurais. Assim, Vilela et al. (2017) demonstra que o crescimento na produção de leite no Brasil é atribuído principalmente à evolução na produtividade e não apenas ao crescimento do rebanho. Nessa questão, a Figura 4 mostra as diferenças de produtividade regional na produção de leite nos municípios mineiros. Além das mesorregiões do Triângulo Mineiro/Alto Paranaíba e do Sul/Sudoeste de Minas, também destacam-se positivamente a mesorregião Central de Minas. Em contrapartida, as mesorregiões do Norte de Minas e do Jequitinhonha apresentaram os municípios com os mais baixos níveis de produtividade.

Os diferenciais de produtividade na produção de leite em Minas Gerais estão relacionados em partes aos fatores edafoclimáticos, tais como, nível de precipitação, clima e qualidade dos solos. Assim, as regiões com maiores níveis de produtividade leiteira são também aquelas que historicamente destacam-se na produção agropecuária no estado. No entanto, os ganhos de produtividade também ocorrem nas regiões com fatores edafoclimáticos não favoráveis, por meio da adoção de tecnologias. Dessa forma, fatores relacionados à escala de produção e modernização dos estabelecimentos rurais são capazes de explicar os diferentes níveis de produtividade leiteira em Minas Gerais (Campos; Pereira; Teixeira, 2014). Desta maneira, esses diferenciais de produtividade regional nos levam a formular a seguinte hipótese:

H1: Mudanças tecnológicas na produção de leite e os seus impactos na produtividade são determinantes do desempenho produtivo local de longo prazo.

A característica de diversidade regional na atividade leiteira em Minas Gerais segue o padrão nacional de heterogeneidade e dispersão espacial (Vilela et al., 2017). Desta forma, as diferenças regionais na produção de leite e das suas atividades complementares na cadeia produtiva são determinadas principalmente pela localização dos estabelecimentos rurais e dos laticínios. Lemos et al. (2003) explicam a localização dessas atividades em Minas Gerais por meio das características de especialização produtiva no Estado. Desse modo, para compreender como as características de especialização regional, associadas aos encadeamentos setoriais na cadeia produtiva do leite, afetam a evolução da produção, construímos a nossa segunda hipótese: 
Figura 3 Produção de leite por mesorregião de Minas Gerais, 2006

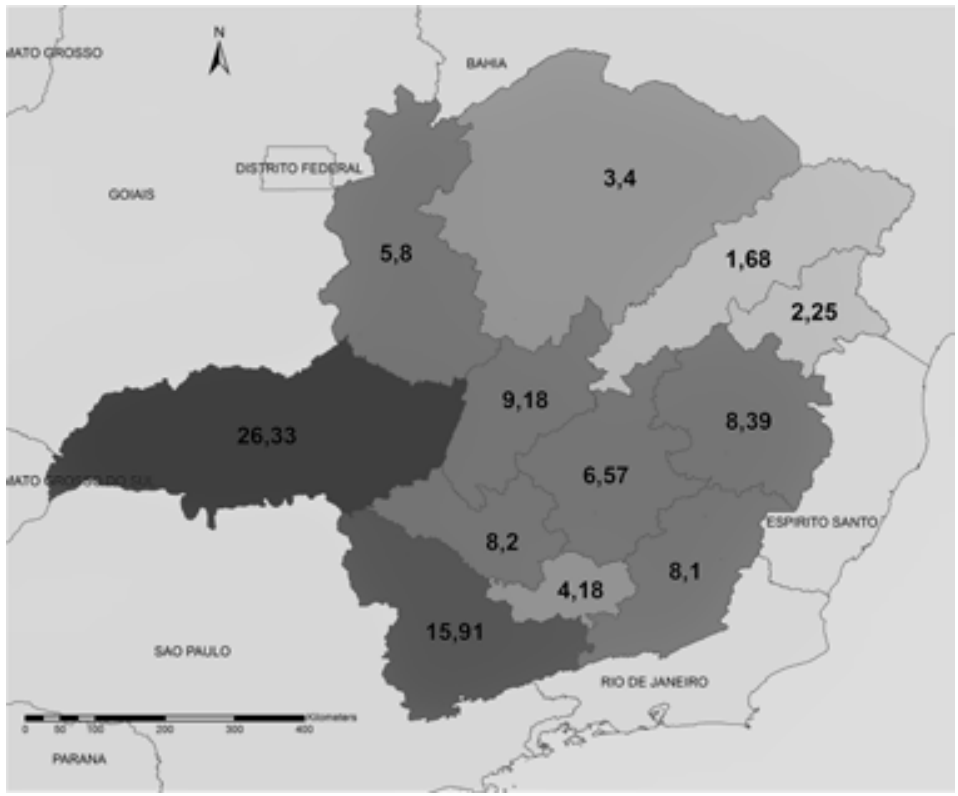

Fonte: Elaborada pelos autores, a partir de dados da PPM/IBGE.

Figura 4 Produtividade (litros de leite por vaca ordenhada), 2006

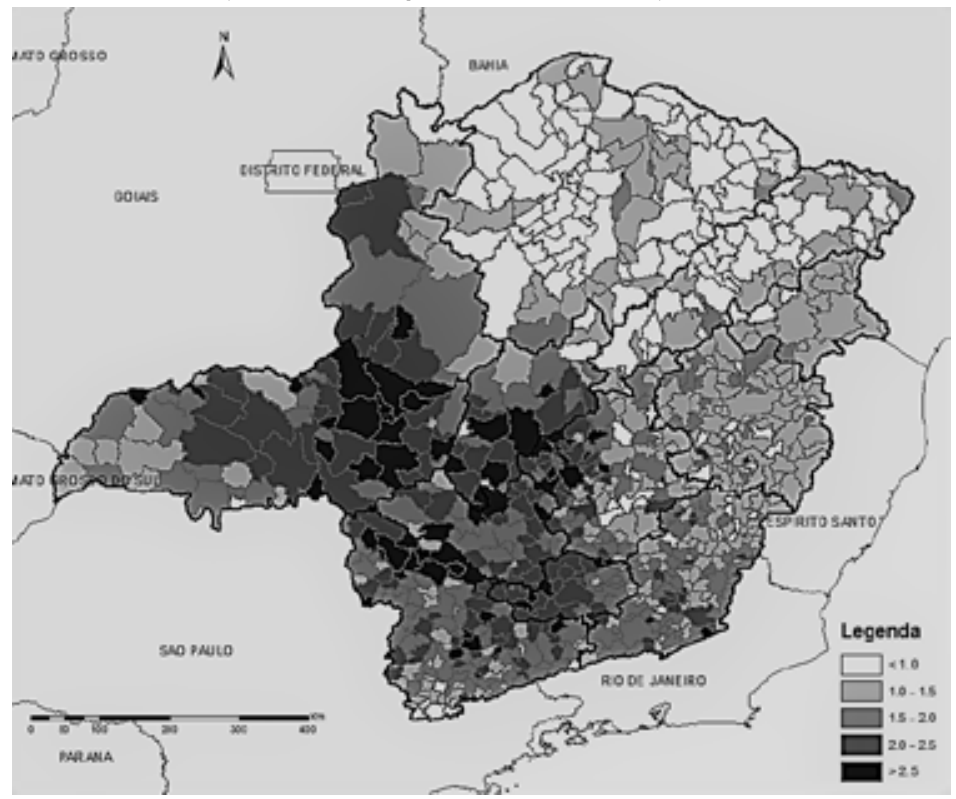

Fonte: Elaborada pelos autores, a partir de dados da PPM/IBGE. 


\section{Figura 5 Crescimento da produção de leite, 2006-2015}

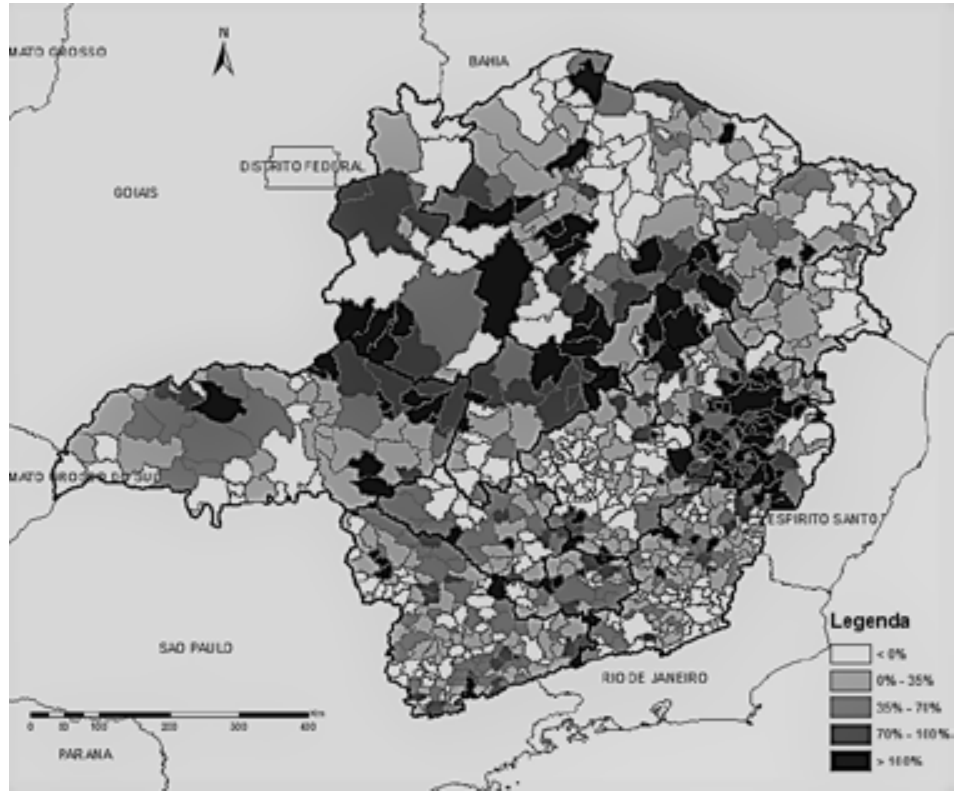

Fonte: Elaborada pelos autores, a partir de dados da PPM/IBGE.

H2a: A estrutura produtiva instalada é capaz de impactar o crescimento de longo prazo da produção de leite.

H2b: A demanda local por produtos lácteos é um determinante do crescimento local da produção.

Por fim, em termos de crescimento da produção de leite, na Figura 5, pode ser visto que esta concentrou-se espacialmente na região central do Estado, principalmente no Vale do Rio Doce, no sul das mesorregiões do Jequitinhonha, Norte e Noroeste de Minas, além de alguns municípios nas mesorregiões do Triângulo Mineiro e da Central Mineira. Esta configuração da cadeia produtiva pode ser um indicativo da importância e da dimensão que esta cadeia de leite vem ganhando. Portanto, a potencialização da mesma pode ser uma forma de aumentar a renda e promover o crescimento econômico nas mesorregiões consideradas menos desenvolvidas de Minas Gerais. Além disso, o crescimento da produção de leite pode se favorecer da existência de transbordamentos espaciais entre os municípios produtores, que impulsiona o crescimento dessa atividade de forma concentrada no espaço. Esses transbordamentos espaciais estão relacionados às características de especialização regional, que permitem 
ganhos relacionados aos retornos crescentes de escala a partir do aproveitamento da estrutura produtiva e tecnológica, que também estão concentradas espacialmente. Em vista disso, para analisar a importância dos fatores espaciais para o crescimento na produção de leite levantamos a nossa terceira hipótese:

H3: O crescimento da produção de leite ocorre de forma concentrada espacialmente nos municípios mineiros.

\section{Abordagem metodológica}

A esratégia empírica a ser seguida, para identificar como aspectos da oferta e da demanda interferem na produção de leite em Minas Gerais, compõe-se da associação de técnicas da análise multivariada, subseções 2.1 e 2.2, aliadas à modelagem que trata do problema da endogeneidade existente na relação entre produção e produtividade do leite, e de eventuais problemas referentes à autocorrelação espacial em função da desagregação espacial dos dados, subseção 2.3 .

\subsection{Análise fatorial: método dos componentes principais}

Para compreender a relação entre os aspectos da oferta e da demanda, que interferem na produção de leite nos municípios mineiros, fez-se o uso da análise fatorial. Esta técnica preza pela redução do número inicial de variáveis a um conjunto de fatores independentes, que possam explicar de maneira simples possíveis relações existentes entre as variáveis originais (Hair Jr. et al., 2005). Tais fatores foram elaborados por meio do método dos componentes principais. Algebricamente, tem-se:

$$
X=\alpha F+U
$$

em que, $X$ corresponde ao vetor de variáveis selecionadas; $\alpha$ remete a matriz de cargas fatoriais; $F$ representa o vetor de fatores (não observáveis); e $U$ refere-se ao vetor dos termos de erros aleatórios.

A resposta da técnica consiste na definição dos coeficientes que relacionam as variáveis originais com os fatores comuns, de forma que cada 
componente principal seja uma combinação linear entre estas variáveis, tidas como independentes entre si. Além disso, esta técnica também fornece o máximo de informação existente na variação contida nos dados (Mingoti, 2007).

Pela matriz de cargas fatoriais ( $\alpha$ ) é possível observar a correlação entre as variáveis originais e cada um dos fatores. Quanto maior a carga fatorial, por conseguinte, maior será a associação entre variável e fator. Outro conceito importante acerca do método é tido em função da comunalidade. Esta é a soma do quadrado das cargas fatoriais, configurada pela proporção da variância de $X$ que auxilia na construção dos fatores. Essa medida varia de 0 a 1 e, quanto mais perto da unidade, maior a importância dos fatores para explicar a variância total das variáveis.

A escolha do número de fatores, de acordo com Hair Jr. et al. (2005) e Mingoti (2007), pode ser feita levando em consideração aqueles que, em conjunto, expliquem pelo menos $70 \%$ da variabilidade comum. Outro critério comumente empregado é o das raízes características. Este critério remete ao somatório dos quadrados das cargas fatoriais de cada variável relacionada ao fator característico. Encontram-se na literatura estudos como Perobelli et al. (1999), Souza e Lima (2003), Melo e Parré (2007) e Castro e Lima (2016) que utilizaram em seus resultados raízes características de fatores maiores que a unidade. Concatenada a escolha do número de fatores, os testes de Bartlett e de Kaiser-Meyer-Olkin (KMO) foram usados para avaliar o refinar do ajustamento do modelo (Johnson; Wichern, 2002).

Definido os fatores, estes ainda foram rotacionados pelo método orthogonal equamax. Desta maneira, espera-se que os escores construídos se tornem "pseudo-índices" responsáveis pela análise do desempenho leiteiro dos municípios mineiros, em um primeiro momento, associado às perspectivas de oferta e de demanda da produção de leite.

\subsection{Análise de clusters}

Para traçar uma tipologia dos municípios mineiros, em termos da produção de leite, foi empregada a análise de clusters (agrupamentos ou aglomeração). Este método formou grupos homogêneos entre os municípios, aos quais foram diferenciados pelos aspectos predominantes em relação a 
oferta e a demanda de leite, associados às características geoecômicas da cadeia produtiva deste produto.

As características de cada grupo serão combinadas por meio de medidas de semelhança, neste caso, medidas de similaridade. Desta forma, busca-se maximizar a homogeneidade interna dos grupos, ao mesmo tempo maximizar a heterogeneidade entre os grupos (Everitt, 1977; Mingoti, 2007).

Entre os procedimentos de associação normalmente empregados na análise de aglomeração, a opção para este trabalho foi pelo método hierárquico de Ward. Neste método, a medida de similaridade utilizada para associar os grupos de municípios foi computada por meio da distância euclidiana ao quadrado entre dois agrupamentos, feita sobre todas as variáveis utilizadas na análise fatorial. Para Johnson e Wichern (2002) e Hair Jr. et al. (2005), o desenvolvimento desta técnica resulta em agrupamentos semelhantes devido a menor variabilidade interna dos grupos, uma vez que em cada estágio de sua aplicação serão aglomerados municípios que apresentarem o menor aumento na soma global das distâncias ao quadrado internamente aos seus devidos agrupamentos.

\subsection{Modelo econométrico}

Para verificar a validade das hipóteses levantadas na segunda seção desse estudo, estimamos um modelo autorregressivo espacial. A estimação do modelo econométrico contou com a utilização dos fatores, obtidos na análise fatorial, associados a produtividade, agindo como determinantes para explicar o crescimento da produção de leite nos municípios mineiros. $\bigcirc$ modelo estimado seguiu a seguinte especificação:

$$
Y_{r}=\beta P_{r}+F_{r} \alpha+\delta X_{r}+\lambda W Y_{r}+\varepsilon
$$

em que, $Y_{r}$ é a taxa de crescimento da produção de leite entre o período de 2006 a 2015 nos $r$ municípios de Minas Gerais; $P_{r}$ é um vetor com uma variável endógena, que representa uma proxy para produtividade regional, medida pelo desempenho produtivo, ou seja, a média de litros de leite por vaca ordenhada no município; $F_{r}$ é uma matriz de variáveis exógenas que representa os fatores obtidos na análise fatorial, que identificam as características relacionas à oferta e à demanda intermediária e final da cadeia 
produtiva do leite; $X_{r}$ é um vetor, exógeno ao modelo, que faz referência a dummy para mesorregião; $W Y_{r}$ é a defasagem espacial da taxa de crescimento da produção de leite nos $r$ municípios de Minas Gerais; $W$ é uma matriz de pesos espaciais, exógena ao modelo; $\varepsilon$ é o termo de erro aleatório e identicamente distribuído; e, finalmente, $\beta, \alpha$ e $\delta$ e $\lambda$ são os coeficientes a serem estimados na regressão.

A inclusão no modelo da defasagem espacial permitiu testar a hipótese de que o crescimento dos municípios vizinhos esteja relacionado ao crescimento local da produção de leite. Deste modo, este modelo espacial expande o modelo padrão ao incluir do lado direito da equação a variável defasada espacialmente. Cada observação dessa nova variável é uma média ponderada dos valores da variável dependente observada para as outras regiões (Anselin, 1988).

A definição de dependência espacial, a partir da noção de similaridade local, ou seja, a determinação dos locais para os quais são correlacionados os valores da variável em questão, é expresso formalmente na matriz de peso espacial. Uma matriz espacial, $W$, possui dimensão $r$ por $r$, com elementos genéricos $w_{i j}$. Nesse estudo, usamos uma matriz de peso espacial do tipo distância, ponderada na linha. Consequentemente, quando $i$ e $j$ são vizinhos, a matriz assume valores positivos, de acordo com a distância geográfica, e caso contrário zero. Por convenção, os elementos da diagonal de $W$ são iguais a zero. A vizinhança geográfica foi definida traçando um limite de distância de até $130 \mathrm{~km}$ do centroide do município. ${ }^{2}$

\subsubsection{Detectando e controlando a endogeneidade}

A variável dependente, no modelo estimado, é o crescimento da produção de leite entre o período de 2006 a 2015. Todas as variáveis explicativas foram utilizadas com ano base de 2006. A escolha de um longo período de tempo é justificada pois espera-se que as variáveis explicativas do modelo, responsáveis por captar as características da oferta e da demanda, exercem um efeito no longo prazo que é capaz de influenciar o crescimento da produção. Além disso, a estratégia de especificação do modelo,

2 Foi testada a sensibilidade do modelo espacial por meio do uso de diferentes matrizes. A escolha pela matriz com limite de distância de $130 \mathrm{~km}$ foi motivada pela a sua aderência ao modelo, em corrigir o problema de dependência espacial. 
utilizando longo intervalo de tempo entre a variável dependente e as variáveis explicativas, visa reduzir possíveis problemas de endogeneidade entre essas variáveis.

No entanto, não se pode descartar a possibilidade de que as variáveis explicativas estejam correlacionadas com o termo de erro do modelo. Além do mais os municípios podem apresentar diferenças persistentes e heterogeneidade em termos de produtividade. Como exemplo, municípios que apresentaram maior produção em 2015 eram susceptíveis de também terem elevada produção em 2006. Logo, é possível a ocorrência do efeito de endogeneidade em função da relação de causalidade existente entre produtividade e crescimento da produção.

Em uma tentativa de verificar a robustez dos resultados da estimação da equação (2), por Mínimos Quadrados Ordinários (MQO), adotamos uma abordagem de variáveis instrumentais. Desse modo, foram empregadas variáveis tecnológicas como instrumentos para o regressor suspeito de ser endógeno, ou seja, a produtividade regional. As variáveis escolhidas para mensurar mudanças tecnológicas foram: número de estabelecimentos que fazem o uso de inseminação artificial; uso de ordenhadeira mecânica; número de estabelecimentos pecuários que fazem o uso de tratores; e uma proxy para investimento em Pesquisa e Desenvolvimento (P\&D) na atividade pecuária, definida em Araújo, Cavalcante e Alves (2009). As diferenças entre as variáveis que influenciam o crescimento da produção de leite e a sua produtividade também já foram discutidas em Embrapa (2011).

Essa simultaneidade implica que o estimador de MQO não seja consistente. Dessa maneira, estimamos um modelo de Mínimos Quadrados em dois Estágios (MQ2E), implementado pelo método dos momentos generalizados com a estratégia de estimação de variáveis instrumentais (IV-GMM). As estimativas foram obtidas através da aplicação de erros padrões robustos em duas etapas do GMM, tal como recomendado por Baum, Schaffer e Sillman (2007). Segundo Cameron e Trivedi (2005), na presença de endogeneidade, o método de MQ2E implementado por IVGMM possibilita estimações mais eficientes e consistentes, quando comparadas ao $\mathrm{MQO}$.

Os testes estatísticos de $J$ de Hansen, para sobreidentificação do modelo, o de endogeneidade e o de Wald foram realizados visando garantir a validação dos instrumentos utilizados para representar a produtividade, além de verificar a aderência e robustez dos resultados obtidos pelo modelo. 
Para tratar do problema de endogeneidade espacial causada pela heterogeneidade regional nos dados, estimamos um modelo linear em cross-section com a especificação Autoregressiva Espacial (SAR). Com esta especificação, o estimador IV-GMM permite identificar o parâmetro do modelo espacial. Desse modo, o método generelizado de Mínimos Quadrados em dois Estágios Espacial permitiu a correta especificação desse modelo (Kelejian; Prucha, 1998, 2004 e 2010).

\section{Base de dados}

Para analisar as diferentes dimensões espaciais da cadeia de produção de leite, identificamos variáveis relacionadas a estrutura de oferta e de demanda nessa cadeia produtiva. Além disso, utilizamos um grupo de variáveis que podem estar relacionadas à estrutura tecnológica e ao crescimento de longo prazo na produção de leite. A descrição completa das variáveis, bem como as suas fontes e respectivos anos de extração, encontram-se dispostas no Quadro 1.

Quadro 1 Definição e fonte das variáveis

\begin{tabular}{l|l|l}
\hline Variável & Descrição & \multicolumn{2}{l}{ Fonte } \\
\hline \multicolumn{1}{l|}{ Análise fatorial e Análise de agrupamento } & \multicolumn{2}{l}{} \\
\hline Fazendas & $\begin{array}{l}\text { Número de estabelecimentos pecuários que } \\
\text { produziram leite. }\end{array}$ & Censo Agropecuário 2006 \\
\hline Rebanho & Número de vacas ordenhadas. & Censo Agropecuário 2006 \\
\hline Emprego & Número de trabalhadores na atividade pecuária. & Censo Agropecuário 2006 \\
\hline Área & $\begin{array}{l}\text { Área dos estabelecimentos pecuários que } \\
\text { produziram leite. }\end{array}$ & Censo Agropecuário 2006 \\
\hline Tanques & $\begin{array}{l}\text { Número de estabelecimentos pecuários que } \\
\text { possuíam tanques para resfriamento de leite. }\end{array}$ & Censo Agropecuário 2006 \\
\hline Laticínios & Número de laticínios. & RAIS 2006 \\
\hline Tamanho laticínios & Número de vínculos nos laticínios. & RAIS 2006 \\
\hline População & População do município. & IBGE 2006 \\
\hline Renda & Massa salarial do município. & RAIS 2006 \\
\hline Comércio leite & $\begin{array}{l}\text { Número de estabelecimento que vendem leite } \\
\text { (comércio no varejo e no atacado). }\end{array}$ & RAIS 2006 \\
\hline Tamanho \\
comércio leite & $\begin{array}{l}\text { Número de vínculos nos estabelecimentos que } \\
\text { vendem leite. }\end{array}$ & RAIS 2006 \\
\hline
\end{tabular}

(continua) 
Quadro 1 (continuação)

\begin{tabular}{|c|c|c|}
\hline Variável & Descrição & Fonte \\
\hline \multicolumn{3}{|c|}{ Modelo econométrico } \\
\hline Produção de leite & Produção de leite (mil litros). & PPM 1975 a 2015 \\
\hline $\begin{array}{l}\text { Inseminação } \\
\text { artificial }\end{array}$ & $\begin{array}{l}\text { Número de estabelecimentos pecuários que } \\
\text { realizaram inseminação artificial. }\end{array}$ & Censo Agropecuário 2006 \\
\hline $\begin{array}{l}\text { Ordenhadeira } \\
\text { mecânica }\end{array}$ & $\begin{array}{l}\text { Número de estabelecimentos pecuários que } \\
\text { possuíam ordenhadeira mecânica. }\end{array}$ & Censo Agropecuário 2006 \\
\hline Tratores & $\begin{array}{l}\text { Número de estabelecimentos pecuários produ- } \\
\text { tores de leite que possuíam tratores. }\end{array}$ & Censo Agropecuário 2006 \\
\hline $\begin{array}{l}\text { Proxy P\&D } \\
\text { pecuária }\end{array}$ & $\begin{array}{l}\text { Número de vínculos em ocupações técnico- } \\
\text {-científicas (Araújo, Cavalcante e Alves, 2009) } \\
\text { no setor de atividade da pecuária em relação ao } \\
\text { total de vínculos na atividade pecuária. }\end{array}$ & RAIS 2006 \\
\hline
\end{tabular}

Fonte: Elaborado pelos autores.

O foco da análise são os 853 municípios de Minas Gerais. A fonte dos dados usados no estudo é o Instituto Brasileiro de Geografia e Estatística (IBGE), por meio do Censo Agropecuário, do Censo Demográfico e da Pesquisa Pecuária Municipal (PPM), e o Ministério do Trabalho, através da Relação Anual de Informações Sociais (RAIS).

A Tabela 1 apresenta o sumário estatístico das variáveis utilizadas na análise fatorial, análise de clusters e no modelo econométrico. Essas variáveis também podem ser encontradas nos trabalhos da Embrapa (2011) e de outros autores como Meyer (1997), Meyer e Braga (1998), Kageyama e Leone (2002), Souza e Lima (2003), Perobelli et al. (2007), Almeida, Perobelli e Ferreira (2008), Borges et al. (2014), Campos, Pereira e Teixeira (2014) e Santos et al. (2014). Em comum, estes autores trataram em seus estudos sobre importantes aspectos para a modernização agropecuária no país.

Para a realização da análise fatorial e da análise de agrupamento, buscou-se escolher variáveis que estivessem relacionadas tanto à oferta de leite quanto à demanda nos municípios, de modo que as suas variações interfiram no crescimento da produção de leite. No que diz respeito ao modelo econométrico, além da variável dependente, produção de leite, também foram empregados os fatores extraídos da análise fatorial e a produtividade. Produtividade esta que, em primeiro estágio, foi representada pela divisão entre litros de leite por vacas e, em um segundo estágio, por instrumentos. 
Tabela 1 Sumário estatístico (número de observações = 853)

\begin{tabular}{|c|c|c|c|c|}
\hline Variáveis $^{a}$ & Média & Desvio Padrão & Mínimo & Máximo \\
\hline Fazendas & 261,516 & 240,498 & 0 & $2.145,000$ \\
\hline Rebanho & $3.721,988$ & $4.391,098$ & 0 & $35.585,000$ \\
\hline Emprego & $1.035,436$ & $1.125,078$ & 0 & $9.292,000$ \\
\hline Área & $25.805,220$ & $41.401,390$ & 0 & $419.819,000$ \\
\hline Tanque & 30,123 & 57,562 & 0 & 571,000 \\
\hline Laticínios & 1,308 & 2,133 & 0 & 22,000 \\
\hline Tamanho laticínio & 25,457 & 81,303 & 0 & $1.005,000$ \\
\hline População & $22.836,290$ & $94.538,400$ & 889,00 & 2.399.920,000 \\
\hline Renda & $4.184 .157,000$ & $50.500 .000,000$ & $31.440,170$ & $1.448 .985 .216,000$ \\
\hline Comércio leite & 4,635 & 29,409 & 0 & 779,000 \\
\hline $\begin{array}{l}\text { Tamanho } \\
\text { comércio leite }\end{array}$ & 25,877 & 246,771 & 0 & $6.934,000$ \\
\hline $\begin{array}{l}\text { Crescimento leite } \\
\text { 2006-2015 }\end{array}$ & 36,164 & 62,510 & $-77,921$ & 354,545 \\
\hline $\begin{array}{l}\text { Produtividade } \\
\text { (litros de leite/vaca) }\end{array}$ & 1,579 & 0,613 & 0 & 4,139 \\
\hline Fator 1 - Oferta & 0,000 & 1,003 & $-4,547$ & 4,574 \\
\hline $\begin{array}{l}\text { Fator } 2 \text { - Demanda } \\
\text { intermediária }\end{array}$ & 0,000 & 1,003 & $-2,464$ & 4,478 \\
\hline Fator 3 - Demanda final & 0,000 & 1,004 & $-1,324$ & 13,481 \\
\hline
\end{tabular}

a Foram realizados testes para identificar a distribuição das variáveis usadas na análise fatorial. Para tornar as suas distribuições próximas à distribuição normal, as variáveis população e renda foram logaritimizadas e as demais variáveis foram transformadas usando a raiz quadrada. As variáveis crescimento do leite e produtividade foram padronizadas para serem usadas na regressão.

Fonte: Elaborado pelos autores.

\section{Resultados}

Os resultados são apresentados e discutidos em três subseções. A primeira subseção mensura as dimensões da cadeia produtiva leiteira em Minas Gerais. No que diz respeito a segunda subseção, esta traça uma tipologia dos municípios mineiros produtores de leite. Finalmente, a terceira subseção aborda os determinantes do crescimento da produção de leite em Minas Gerais. 


\subsection{Dimensões da cadeia produtiva do leite}

Tendo como um dos interesses deste trabalho caracterizar as dimensões da cadeia produtiva do leite em Minas Gerais, optou-se por realizar a técnica da análise fatorial empregando a abordagem de componentes principais, com rotação pelo método orthogonal equamax. Desta maneira, foram agregadas observações coletadas para 11 variáveis originais referentes ao ano de 2006. Os resultados da análise fatorial são apresentados na Tabela 2.

A opção pelo número de fatores referentes a análise foi feita com base naqueles que apresentaram valores de raízes características (Autovalores) maiores que a unidade. Diante disso, foram computados três fatores que satisfizeram esse critério: o primeiro fator explicou $29,3 \%$ da variância; o segundo $28,8 \%$; e o terceiro, $25,4 \%$. Ao todo, os três fatores compilaram $83,5 \%$ da variância total das variáveis originais.

A Tabela 2 também evidencia a distribuição das variáveis originais entre os três fatores criados. Em geral é recomendado que sejam definidos valores de corte aproximados, para determinar se algum fator explica consideravelmente uma variável. Tomando como referência Hair Jr. et al. (2005) e Mingoti, (2007), optou-se por valores acima de 0,650. Desta forma, os fatores puderam ser nomeados de acordo com as variáveis que melhor explicaram.

Testando o refinamento obtido com os três fatores, o critério de Kaiser-Meyer-Olkin (KMO) apresentou resultado de 0,775. O teste de Bartlett resultou em uma estatística qui-quadrado com $p$-valor próximo a zero. A Figura 6, por sua vez, apresenta o enquadramento após a rotação do método, levando em consideração o resultado dos coeficientes. Com base em Hair Jr. et al. (2005) e Mingoti (2007), as análises indicaram boa adequabilidade dos dados para o prosseguimento deste trabalho.

$\mathrm{O}$ primeiro fator, F1, mostrou-se fortemente relacionado de maneira positiva às variáveis de fazendas, rebanho, emprego e área. O número de estabelecimentos pecuários que produziram leite, a área média destes estabelecimentos, bem como o tamanho do rebanho e o número de empregos gerados estão relacionados à capacidade de produção no campo. Levando em consideração esta ótica, F1 pode ser denominado como fator de "oferta".

A Figura 7a mostra que, apesar das mesorregiões Norte e o Nordeste de Minas Gerais concentram pequenos percentuais da produção de leite 
estadual (Figura 2), os seus municípios apresentam alta capacidade de produção de leite. Portanto, relaciona-se que, devido à baixa produtividade (Figura 3) esses municípios não conseguem reverter a capacidade instalada em alta participação na produção de leite.

Tabela 2 Análise fatorial: método de componentes principais ${ }^{\mathrm{a}}$

\begin{tabular}{lrrrrr}
\hline Variáveis & Fator 1 & Fator 2 & Fator 3 & $\begin{array}{r}\text { Variância dos } \\
\text { resíduos }\end{array}$ \\
\hline Fazendas & 0,844 & 0,342 & 0,097 & 0,161 \\
\hline Rebanho & $\mathbf{0 , 7 3 6}$ & 0,601 & 0,026 & 0,097 \\
\hline Emprego & $\mathbf{0 , 9 1 9}$ & 0,123 & 0,121 & 0,125 \\
\hline Área & $\mathbf{0 , 8 3 1}$ & 0,250 & 0,028 & 0,246 \\
\hline Tanque & 0,486 & 0,662 & $-0,004$ & 0,326 \\
\hline Laticínios & 0,083 & 0,856 & 0,289 & 0,178 \\
\hline Tamanho laticínio & 0,088 & 0,846 & 0,302 & 0,185 \\
\hline População & 0,316 & 0,240 & 0,850 & 0,121 \\
\hline Renda & 0,152 & 0,376 & 0,814 & 0,174 \\
\hline Comércio leite & $-0,025$ & 0,287 & 0,911 & 0,088 \\
\hline Tamanho comércio leite & $-0,055$ & 0,265 & 0,898 & 0,120 \\
\hline Autovalores & 3,219 & 3,167 & 2,793 & \\
\hline Proporção da variância & 0,293 & 0,288 & 0,254 & \\
\hline
\end{tabular}

${ }^{a}$ Rotação dos fatores: orthogonal equamax.

Nota: Teste LR: Prob $(\chi 2)=0,000$. Medida da adequação da amostragem (Teste de Kaiser-Meyer-Olkin $-K M O)=0,775$.

Fonte: Elaborado pelos autores.

Já o segundo fator, F2, relaciona-se fortemente de maneira positiva com as variáveis de laticínio, tamanho do laticínio e tanques. Assim, esse fator foi nomeado de "demanda intermediária", uma vez que, são os laticínios as unidades produtivas que realizam a transformação do leite in natura em seus subprodutos, como leites desnatados, semidesnatados, integrais, além de queijos, manteigas, requeijões, dentre outras variedades.

A distribuição espacial dos municípios mineiros, no tocante a demanda intermediária, pode ser vista na Figura $7 b$. Por esta Figura, percebe-se grande concentração destas atividades na região centro-sul do Estado, sobretudo na mesorregião do Triângulo Mineiro/Alto Paranaíba. 
Figura 6 Dimensões da cadeia produtiva do leite: análise fatorial 6a Fator 1

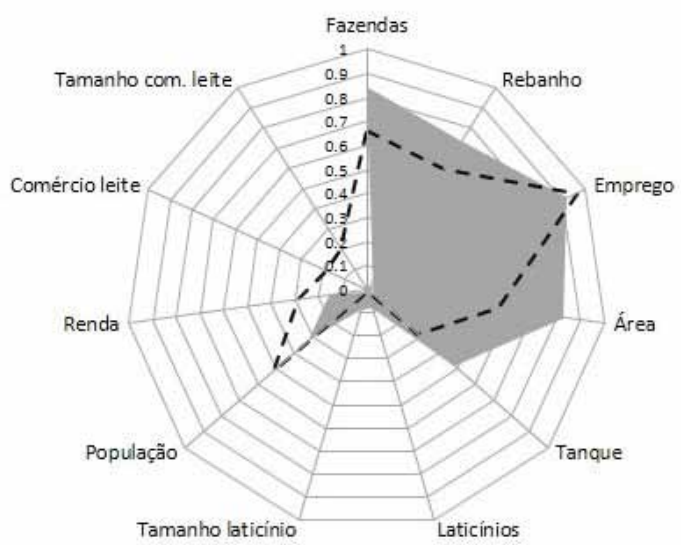

6b Fator 2

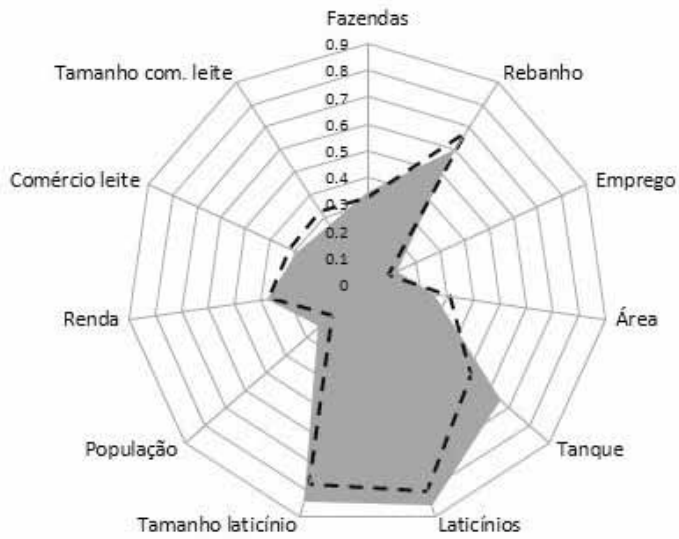

$6 c$ Fator 3

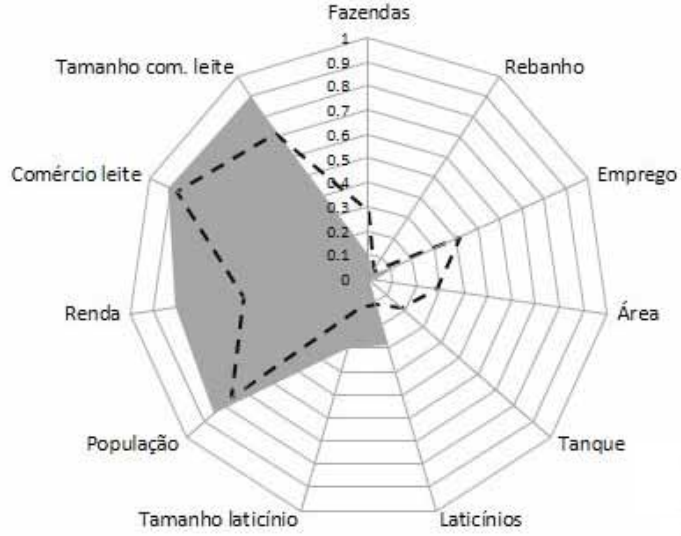

Fonte: Elaborado pelos autores. 
Figura 7 Dimensões da cadeia produtiva do leite: municípios de Minas Gerais 7a Oferta

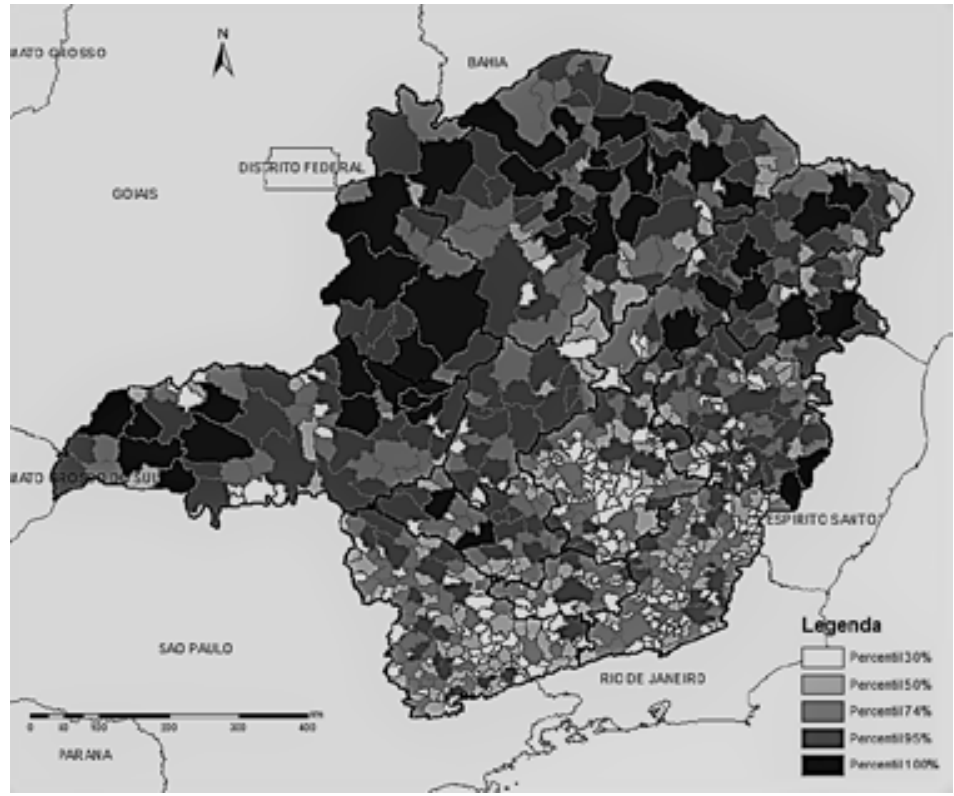

\section{7b Demanda intermediária}

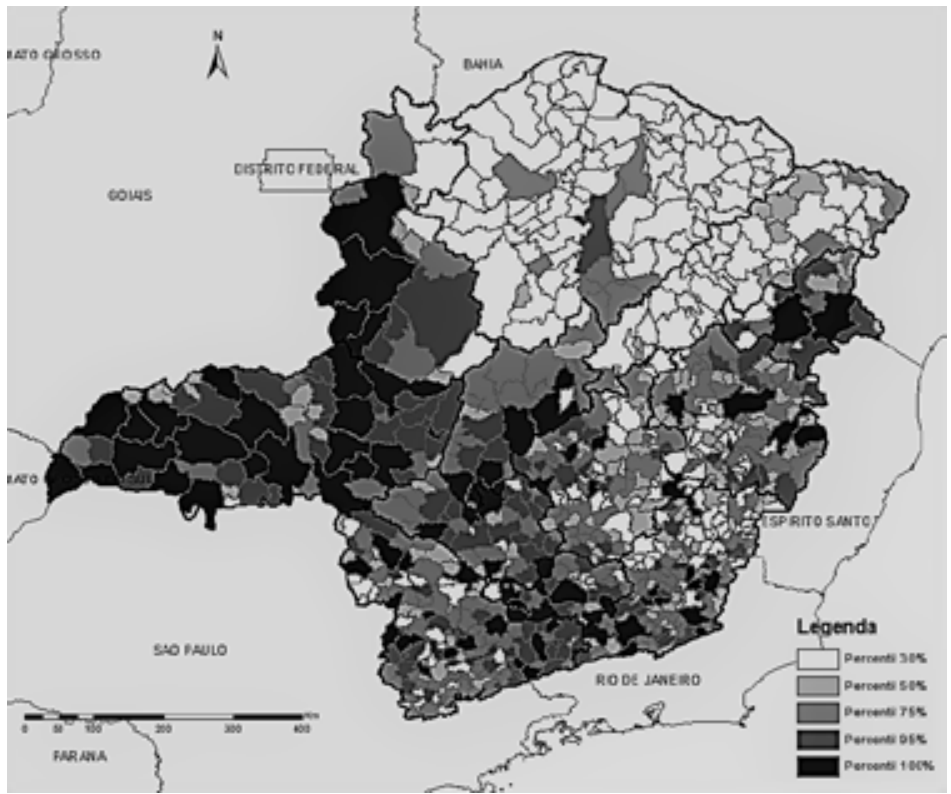




\section{7c Demanda final}

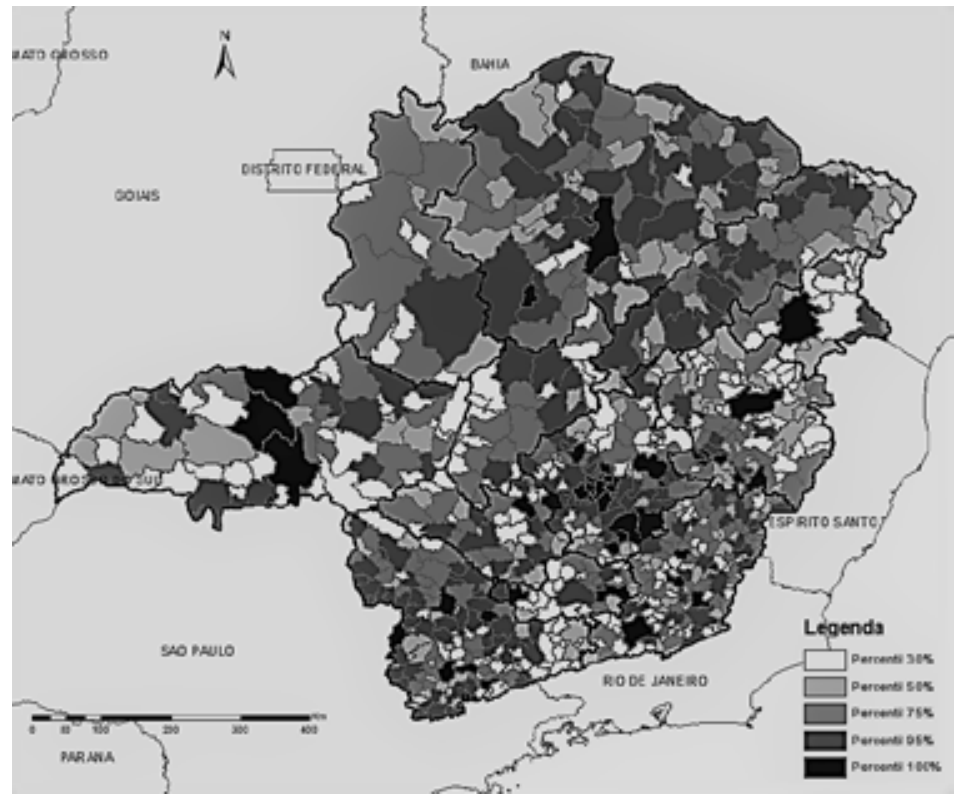

Fonte: Elaborado pelos autores.

O terceiro e último fator, F3, correlacionou-se de maneira positiva e forte com as variáveis de população, renda, comércio de leite e tamanho do comércio de leite. Por ser estritamente conectado as variáveis tidas na literatura econômica como referentes à demanda, este fator pode ser denominado de "aspectos da demanda final". Quanto maior a população e a renda, espera-se que, em média, maiores sejam o número de comércios que vendam leite, bem como o número de vínculos empregatícios gerados por estes comércios.

A Figura 7c mostra que os municípios mineiros, como um todo, são grandes demandantes de leite, apresentando uma distribuição homogênea da demanda deste produto por todo o Estado. Esta informação não só reforça a importância da cadeia leiteira, bem como demonstra a grande capacidade de absorção do produto em Minas Gerais.

\subsection{Tipologia dos munícipios mineiros produtores de leite}

Para construir uma tipologia dos municípios mineiros produtores de leite foi empregada a análise de clusters ou agrupamento, utilizando as 11 
variáveis incluídas na análise fatorial. Por meio das medidas de similaridade foi possível agrupar os 853 municípios mineiros em oito categorias: grande oferta de leite; oferta de leite e baixa renda; propriedades rurais e laticínios de grande porte; propriedades rurais e laticínios de médio porte; propriedades rurais e laticínios de pequeno porte; centros urbanos; municípios com baixa participação na cadeia de produção; e municípios com baixo nível de renda.

A Tabela 3 fornece informações acerca do percentual médio da distribuição de cada variável nos grupos formados, bem como, para cada grupo, o número de municípios, o percentual da produção de leite, a remuneração média e as características da participação no PIB.

O Quadro 2 apresenta exemplos dos 10 principais municípios que compõem as oitos tipologias identificadas na análise de clusters. Já a distribuição espacial dos municípios mineiros, conforme os agrupamentos, encontra-se na Figura 8. De maneira geral, percebe-se que nenhuma mesorregião é composta apenas por um tipo de agrupamento, o que reflete a complexidade da cadeia do leite no estado. Todavia, é possível destacar a importância dos municípios do Triângulo Mineiro/Alto Paranaíba, Central Mineira e Noroeste de Minas, além dos municípios localizados no extremo norte das mesorregiões Norte de Minas, Jequitinhonha e Vale do Mucuri, para os fatores relacionados à oferta de leite. Enquanto os municípios no Sul/Sudoeste de Minas, Zona da Mata e Vale do Rio Doce são especializados principalmente nas atividades de beneficiamento do leite (demanda intermediária).

A partir da tipologia dos municípios mineiros podemos observar a seguinte configuração da cadeia de produção do leite. Os 77 municípios classificados no Grupo (1) são responsáveis por $24,3 \%$ da produção de leite. Nessa tipologia está concentrada importante parcela da capacidade instalada para a produção de leite no estado de Minas Gerais, com 17,0\% das propriedades, $22,0 \%$ do rebanho e 18,6\% dos empregos na pecuária. Esses municípios são caracterizados também por estabelecimentos rurais de médio porte (média de 66,1 ha por estabelecimento).

O Grupo (2) concentra 98 municípios e $14,6 \%$ da produção de leite estadual. Esses municípios possuem estabelecimentos de médio porte (média de 51,0 ha por estabelecimento). Mas, essa tipologia, diferente do Grupo (1), é marcada por municípios com baixo nível de renda e menor nível de produtividade na produção de leite. No Grupo (2) estão os 
municípios com a segunda menor participação no PIB (6,2\%) e na renda $(4,8 \%)$. Embora estejam distribuídos em todas as mesorregiões do Estado, estes municípios concentram-se principalmente no Norte de Minas e no Vale do Jequitinhonha, regiões marcadas por elevado nível pobreza (Figura 6). Assim, os municípios pertencentes a esse Grupo devem ser observados com atenção pelos formuladores de política, pois iniciativas com o objetivo de aumentar a produtividade leiteira nessa região poderiam aproveitar de uma grande capacidade já instalada para produção (número de estabelecimentos, vacas ordenhadas, área da propriedade e empregos). Além disso, esse tipo de política pode se tornar um instrumento para o aumento da renda na região, devido aos efeitos de encadeamentos produtivos, na relação de insumo-produto, impulsionados pela atividade pecuária - como destacado para a região Sul do Brasil por Montoya e Finamore (2005).

\section{Quadro 2 Tipologia por municípios selecionados}

\begin{tabular}{l|l|l}
\hline Grupo & Classificação & Municípios (top 10) \\
\hline $\mathbf{( 1 )}$ & $\begin{array}{l}\text { Grande oferta } \\
\text { de leite }\end{array}$ & $\begin{array}{l}\text { Bom Despacho, Frutal, Ibiá, Juiz de Fora, Luz, Passos, Patrocínio, } \\
\text { Perdizes, Pompéu, Sacramento. }\end{array}$ \\
\hline $\mathbf{( 2 )}$ & $\begin{array}{l}\text { Oferta de leite } \\
\text { e baixa renda }\end{array}$ & $\begin{array}{l}\text { Araxá, Bom Sucesso, Cássia, Lavras, Martinho Campos, Oliveira, } \\
\text { São Gotardo, São João Del Rei, Serra do Salitre, União de Minas. }\end{array}$ \\
\hline $\mathbf{( 3 )}$ & $\begin{array}{l}\text { Propriedades } \\
\text { rurais e laticínios } \\
\text { de grande porte }\end{array}$ & $\begin{array}{l}\text { Coromandel, Curvelo, Governador Valadares, Montes Claros, Para- } \\
\text { catu, Patos de Minas, Teófilo Otoni, Uberaba, Uberlândia, Unaí. }\end{array}$ \\
\hline (4) & $\begin{array}{l}\text { Propriedades } \\
\text { rurais e laticínios } \\
\text { de médio porte }\end{array}$ & $\begin{array}{l}\text { Alpinópolis, Arcos, Barbacena, Divinópolis, Itabira, Itaúna, Lagoa da } \\
\text { Prata, Paraopeba, São João Batista do Glória, Três Corações. }\end{array}$ \\
\hline $\mathbf{( 5 )}$ & $\begin{array}{l}\text { Propriedades } \\
\text { rurais e laticínios } \\
\text { de pequeno porte }\end{array}$ & $\begin{array}{l}\text { Betim, Conceição do Rio Verde, Elói Mendes, Guarani, Moema, } \\
\text { Muzambinho, Palma, Pequi, São Gonçalo do Sapucaí, São Sebas- } \\
\text { tião do Paraíso. }\end{array}$ \\
\hline (6) & $\begin{array}{l}\text { Centros urbanos } \\
\text { Belo Horizonte, Contagem, Coronel Fabriciano, Ibirité, Ipatinga, } \\
\text { Ribeirão das Neves, Sabará, Santa Luzia, Varginha, Vespasiano. }\end{array}$ \\
\hline (7) & $\begin{array}{l}\text { Municípios com } \\
\text { baixa participação } \\
\text { na cadeia produtiva }\end{array}$ & $\begin{array}{l}\text { Araporã, Belo Oriente, Conselheiro Lafaiete, Fronteira, Itatiaiuçu, } \\
\text { Manhuaçu, Pedro Leopoldo, Poços de Caldas, São José da Barra, } \\
\text { Viçosa. }\end{array}$ \\
\hline (8) & $\begin{array}{l}\text { Municípios com } \\
\text { baixo nível de renda }\end{array}$ & $\begin{array}{l}\text { Antônio Carlos, Caetanópolis, Caeté, Capelinha, Conceição das Ala- } \\
\text { goa, Conquista, Diamantina, Indianópolis, Itaobim, Volta Grande. }\end{array}$ \\
\hline
\end{tabular}

Fonte: Elaborado pelos autores. 


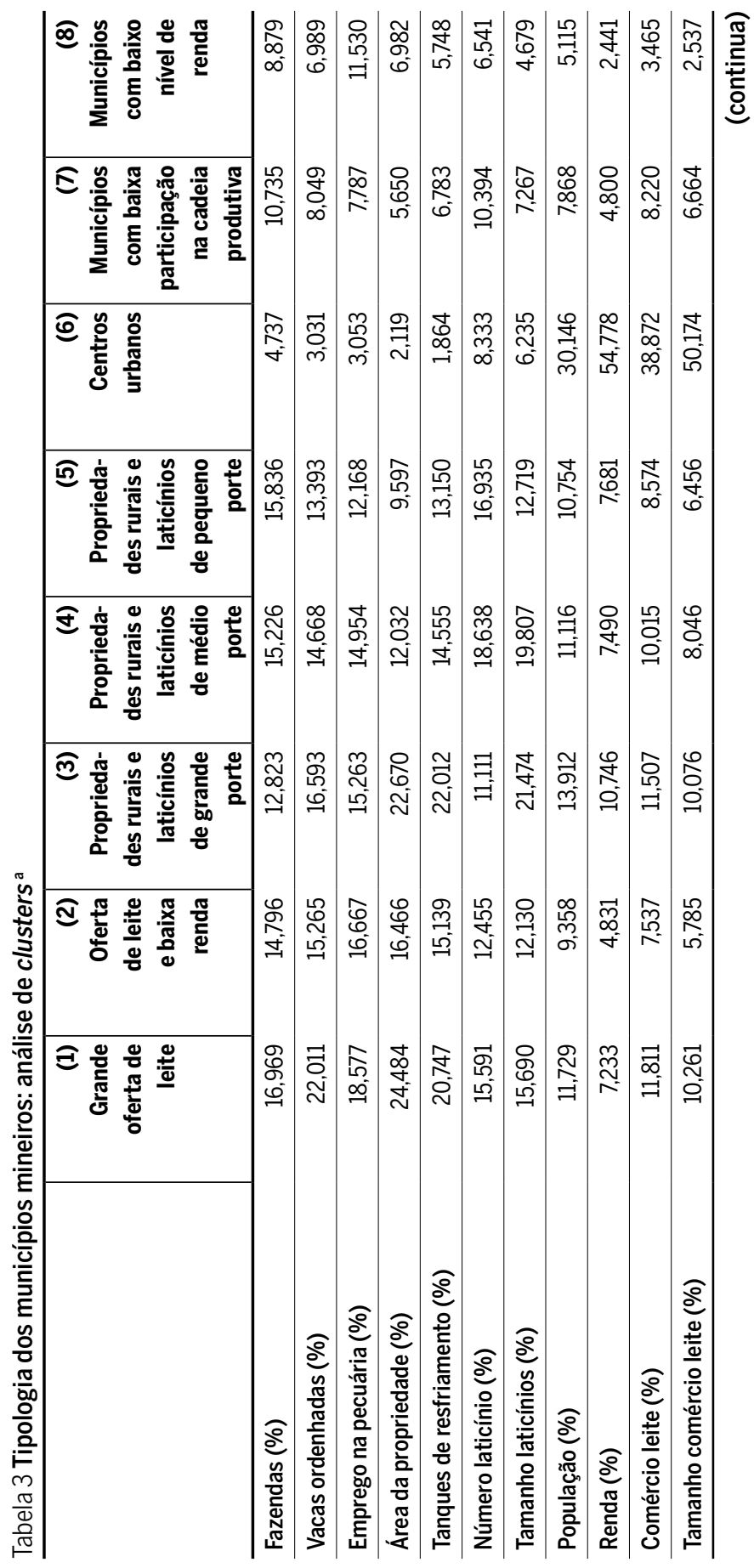




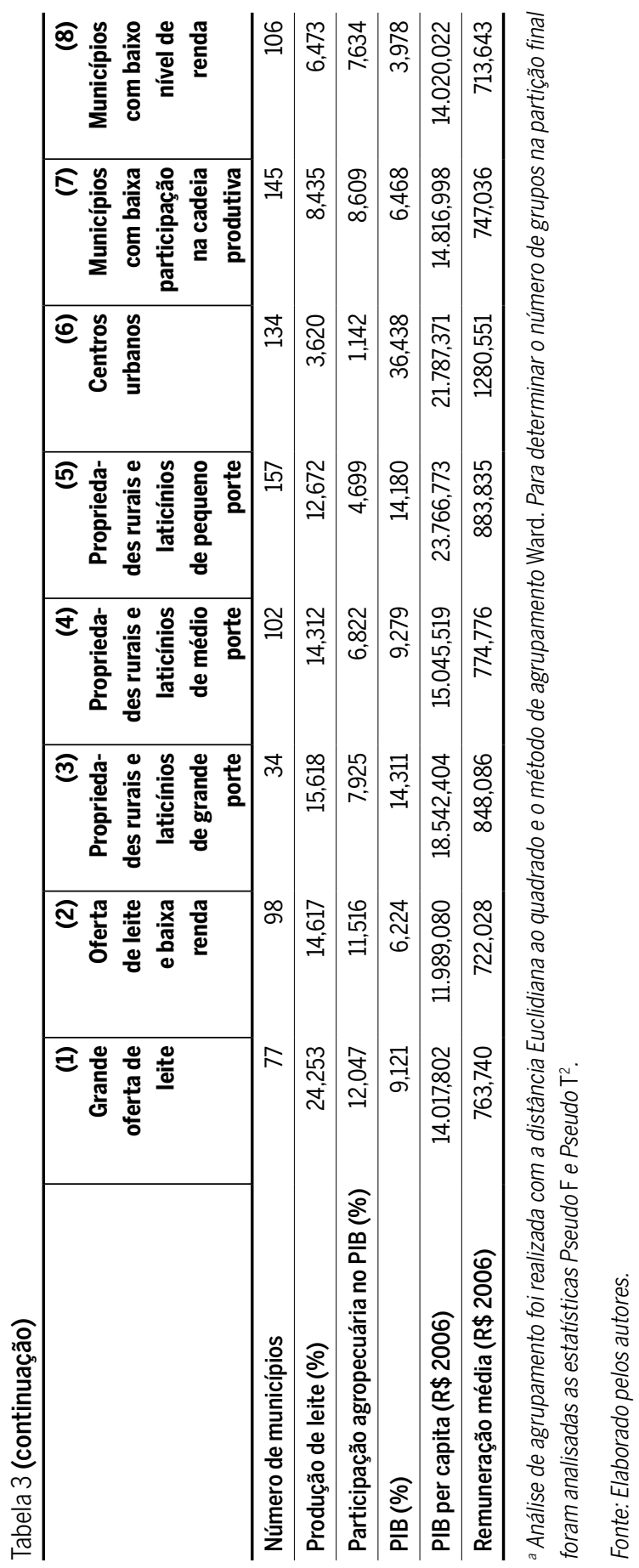


Figura 8 Tipologia dos municípios mineiros: distribuição espacial a partir da análise de clusters

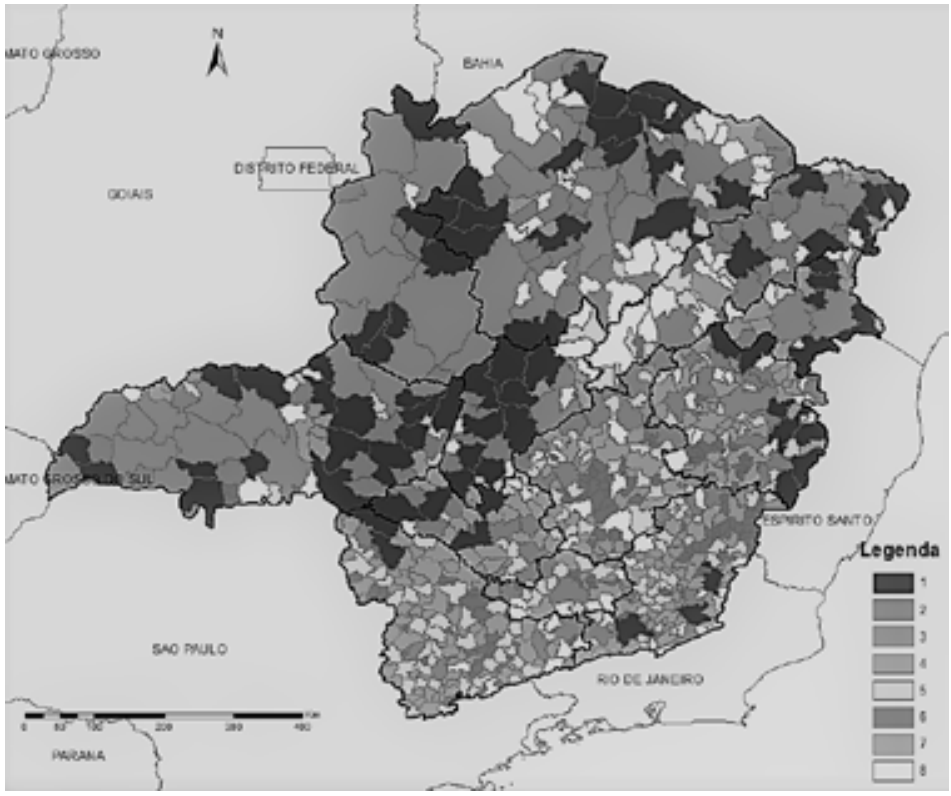

Fonte: Elaborado pelos autores.

O Grupo (3) é formado por 34 municípios, responsáveis por 15,6\% da produção estadual de leite. Esses municípios podem ser considerados "peças-chave" da cadeia produtiva do leite em Minas Gerais, pois concentram importantes componentes da oferta e da demanda intermediária. Essa tipologia é marcada por grandes estabelecimentos pecuários, que concentram apenas 12,8\% das fazendas, mas 22,7\% da área total (média de 81,1 ha por estabelecimento). Neste Grupo, estão também os grandes laticínios do Estado, que embora possuam apenas $11,1 \%$ do número de indústrias, empregam 21,5\% da mão de obra (média de 38 empregos por laticínio em 2006) e concentram 22,0\% dos tanques de resfriamento. Esses municípios possuem também elevado PIB per capita ( $\mathrm{R} \$ 18.542)$ e remuneração no emprego formal (média de $\mathrm{R} \$ 848$ ).

Os municípios classificados nos Grupos (4) e (5) são especializados nas atividades relacionadas à demanda intermediária da cadeia produtiva do leite. Essa tipologia concentra a maior parte das indústrias de laticínios (18,6\% e 16,9\%, respectivamente). A principal diferença entre essas duas tipologias é o padrão das propriedades rurais, dos laticínios e as vocações 
produtivas das cidades. Enquanto no Grupo (4) estão as propriedades com tamanho médio de 36,2 ha e laticínios que possuem em média 21 empregados, no Grupo (5) as propriedades possuem tamanho médio de 27,8 ha e laticínios com 15 empregados, em média. Nas vocações produtivas, o Grupo (4), formado por 102 municípios, concentra 14,3\% da produção de leite e $9,28 \%$ do PIB mineiro, além disso, 6,8\% do seu PIB tem origem nas atividades agropecuárias. Enquanto o Grupo (5) é formado por 157 municípios voltados principalmente para as atividades urbanas, que produzem $12,7 \%$ do leite no Estado e apenas 4,7\% do seu PIB tem origem nas atividades agropecuárias. Contudo, estes são responsáveis por $14,2 \%$ do PIB total de Minas Gerais.

O Grupo (6) é formado por 134 municípios, pertencentes às áreas urbanas, que apresentam elevada demanda final por leite. Esses municípios, além de possuírem alta renda per capita $(\mathrm{R} \$ 21.787$ ) e maiores salários (média de $R$ \$ 1.280), concentram $30,2 \%$ da população e $54,8 \%$ da massa salarial dos empregos formais em Minas Gerais. ${ }^{3}$

O Grupo (7) é formado por 145 municípios, que são importantes para a produção e o consumo de leite no estado. No entanto, esses municípios são caracterizados por pequenas propriedades (em média 24,1 ha por estabelecimento) e pequenas indústrias de beneficiamento do leite (em média 14 funcionários por laticínio). Enquanto o Grupo (8) concentra 106 municípios com o menor nível de renda per capita no estado. No entanto, embora pouco conectados à cadeia de produção do leite pelo lado da demanda, esses municípios concentram 8,9\% dos estabelecimentos rurais e 11,5\% dos empregos gerados na pecuária.

Em síntese, podemos observar que o padrão de produção de leite em Minas Gerais constitui-se principalmente por propriedades rurais e laticínios de médio e pequeno porte. Resultado este que caminha em direção oposta a percepção mundial da cadeia de leite estabelecida na análise da Embrapa Gado de Leite (Embrapa, 2011).

3 O município de Belo Horizonte, localizado na tipologia "Centros Urbanos", no Grupo (6), concentra $16,9 \%$ do PIB, $12,3 \%$ da população e $40,6 \%$ da massa salarial dos empregos formais no estado de Minas Gerais. A importância de Belo Horizonte infla as medidas dessa tipologia. No entanto, caso esse município fosse retirado da análise essa tipologia continuaria concentrando municípios que teriam em comum, além da baixa produção de leite, alto nível de renda - concentrando $19,5 \%$ do $\mathrm{PIB}, 17,8 \%$ da população e $14,2 \%$ da massa salarial dos empregos formais. 


\subsection{Determinantes do crescimento da produção de leite em Minas}

\section{Gerais}

Esta seção discute os resultados da estimação da Equação (2). O objetivo é identificar como as dimensões da cadeia de produção do leite e a produtividade estão relacionadas com o crescimento da produção nos municípios de Minas Gerais. Os resultados estão dispostos na Tabela 4.

Preliminarmente, estimamos o modelo de determinantes do crescimento da produção por $\mathrm{MQO}$ com erros padrões robustos. Por este modelo verifica-se que apenas o fator de oferta e o de demanda final são estatisticamente significativos. Entretanto, sob a hipótese de endogeneidade, as estimações por $\mathrm{MQO}$ tornam-se viesadas. Para corrigir este problema, Cameron e Trivedi (2005) recomendam adotar métodos como o IV-GMM, uma vez que possibilita estimações eficiente e consistentes.

Dessa maneira, o Modelo 2 na Tabela 4 apresenta os resultados da estimação por GMM com variáveis instrumentais. Neste modelo, todas as variáveis foram estatisticamente significativas. As estatísticas de controle e refinamento como o Teste $J$ de Hansen para sobreidentificação do modelo, o teste de endogeneidade e o teste de Wald mostraram perfeita adequação do IV-GMM. Portanto, podemos concluir que os resultados são robustos, sugerindo que qualquer endogeneidade restante nas regressões, com origem na simultaneidade entre as variáveis, é pouco provável para explicar os resultados centrais.

Tabela 4 Determinantes do crescimento de longo prazo da produção de leite nos municípios mineiros

\begin{tabular}{lrr}
\hline $\begin{array}{l}\text { Variável dependente: Crescimento da produção de leite } \\
\text { (2006-2015) }\end{array}$ & $\begin{array}{r}\text { Modelo 1 } \\
\text { OLS }\end{array}$ & $\begin{array}{r}\text { Modelo 2 } \\
\text { IV-GMM }\end{array}$ \\
\hline Produtividade (litros de leite por vaca ordenhada) & 0,027 & $* * * 0,221$ \\
\hline Fator 1 (Oferta) & $(0,038)$ & $(0,074)$ \\
\hline Fator 2 (Demanda intermediária) & $(0,033)$ & $(0,033)$ \\
\hline Fator 3 (Demanda final) & $-0,057$ & $* * *-0,152$ \\
& $(0,038)$ & $(0,048)$ \\
\hline & $* *-0,083$ & $* * * 0,090$ \\
& $(0,033)$ & $(0,034)$ \\
\hline
\end{tabular}


Tabela 4 (continuação)

\begin{tabular}{|c|c|c|}
\hline $\begin{array}{l}\text { Variável dependente: Crescimento da produção de leite } \\
(2006-2015)\end{array}$ & $\begin{array}{r}\text { Modelo } 1 \\
\text { OLS }\end{array}$ & $\begin{array}{r}{\text { Modelo } 2^{\mathrm{a}}}^{\text {IV-GMM }}\end{array}$ \\
\hline \multirow[t]{2}{*}{ Dummy para região do Vale do Rio Doce } & $* * * 0,911$ & $* * * 0,984$ \\
\hline & $(0.102)$ & $(0,123)$ \\
\hline \multirow[t]{2}{*}{ Constante } & $* * *-0,109$ & $* * *-0,120$ \\
\hline & $(0,035)$ & $(0,034)$ \\
\hline \multirow[t]{2}{*}{ Hansen J overidentification test statistic } & . & $x^{2}=5,964$ \\
\hline & ${ }^{\circ}$ & $p=0,113$ \\
\hline \multirow[t]{2}{*}{ First-stage regression } & . & $F=11,436$ \\
\hline & . & $p=0,000$ \\
\hline \multirow[t]{2}{*}{ Teste de endogeneidade } & & $x^{2}=6,438$ \\
\hline & & $p=0,011$ \\
\hline Número de observações & 853 & 853 \\
\hline $\mathrm{R}^{2}$ & 0,104 & 0,077 \\
\hline$F$ & $* * * 19,600$ & \\
\hline Wald $\chi^{2}$ & & $* * * 80,790$ \\
\hline
\end{tabular}

a As estimativas foram obtidas aplicando o estimador IV-GMM em dois estágios por meio da rotina ivregress no Stata. Os instrumentos IV-GMM no Modelo 2 incluem variáveis para o uso de inseminação artificial; uso de ordenha mecânica; número de estabelecimentos com atividade pecuária que possuem tratores; e proxy para P\&D na atividade pecuária.

Nota: Erro padrão robusto entre parênteses. Nível de significância: *** $p<0,01$, ** $p<0,05 e{ }^{*} p<0,1$. Fonte: Elaborado pelos autores.

Os resultados das estimativas por IV-GMM são diferentes das estimativas por MQO. A produtividade regional, após ser instrumentalizada por variáveis que captam a adoção de tecnologias na produção de leite, passou a apresentar um efeito positivo e altamente significativo sobre o crescimento da produção local (Modelo 2 - Tabela 4). Esse resultado reforça as observações realizadas por Souza e Lima (2003), Perobelli et al. (2007), Almeida, Perobelli e Ferreira (2008) e Campos, Pereira e Teixeira (2014) a respeito das mudanças tecnológicas e do aumento da produtividade regional no setor agropecuário. Consequentemente, podemos confirmar a nossa primeira hipótese de pesquisa (H1).

A variável de oferta, especificada através do Fator 1, apresentou efeito positivo sobre o crescimento da produção de leite. Assim, temos indícios de que o crescimento da produção entre 2006-2015 foi concentrado naque- 
les municípios que possuíam maior capacidade instalada para produção. Desse modo, confirmamos o primeiro tópico da nossa segunda hipótese (H2a). O coeficiente da demanda intermediária (Fator 2), após a estimação do modelo que corrige o problema de endogeneidade, tornou-se estatisticamente significativo e com efeito negativo sobre o crescimento local. Enquanto a demanda final (Fator 3) apresentou efeito negativo e significativo. Os coeficientes negativos para as variáveis relacionadas à demanda (intermediária e final) podem ser interpretados como um efeito resultante do mercado consumidor de leite não estar necessariamente localizado nas regiões com maior nível de crescimento da produção no período analisado. Assim, os Fatores 2 e 3 nos levam a rejeitar o segundo tópico da segunda hipótese (H2b). Portanto, esses resultados nos permitem confirmar em partes a nossa segunda hipótese de pesquisa, ou seja, a cadeia produtiva do leite - e os seus encadeamentos setoriais - são importantes para explicar o crescimento local da produção, no entanto, o principal mercado consumidor está fora das regiões produtoras.

O coeficiente da variável dummy para os municípios da mesorregião do Vale do Rio Doce foi positivo e estatisticamente significativo. Esse resultado sugere forte tendência de crescimento da produção nesses municípios. Variáveis dummies para as demais mesorregiões foram testadas, no entanto, levando em consideração o princípio da parcimônia, optamos por manter na estimação apenas a variável dummy com o maior coeficiente estatisticamente significativo.

O crescimento local da produção de leite também pode ser explicado pelo desempenho dos municípios vizinhos. Essa relação de dependência espacial, caso não seja controlada, pode ser uma fonte adicional de endogeneidade na especificação do modelo. Desse modo, realizamos o Teste Anselin-Kelejian nos resíduos do modelo IV-GMM e detectamos a existência de efeitos de endogeneidade espacial nas estimações (Modelo 3 - Tabela 5).

Após a implementação do procedimento completo para avaliação de modelos espaciais ${ }^{4}$, tem-se que a melhor especificação se deu pelo Modelo Autorregressivo Espacial (Spatial Autoregressive - SAR). Este atendeu a dois critérios: não apresentou autocorrelação espacial em seus resíduos, ao mesmo tempo que exibiu o menor critério de informação, quando comparado a outros modelos que também não foram espacialmente autocor- 
relacionados. Em adição, o teste de Anselin-Kelejian para dependência espacial constatou que o modelo IV-GMM-SAR, estimado por meio da matriz de variância e covariância robusta de White, foi capaz de eliminar a endogeneidade espacial.

Tabela 5 Determinantes do crescimento de longo prazo da produção de leite nos municípios mineiros - modelo espacial ${ }^{a}$

\begin{tabular}{lr|r}
\hline $\begin{array}{l}\text { Variável dependente: Crescimento da produção de leite } \\
\text { (2006-2015) }\end{array}$ & $\begin{array}{r}\text { Modelo 3 } \\
\text { IV-GMM }\end{array}$ & $\begin{array}{r}\text { Modelo 4 }^{\text {c }} \\
\text { IV-GMM-SAR }\end{array}$ \\
\hline Produtividade (litros de leite por vaca ordenhada) & $0,195^{* * *}$ & $\begin{array}{r}0,106^{* *} \\
(0,074)\end{array}$ \\
\hline Fator 1 (Oferta) & $0,077^{* *}$ & $0,058^{*}$ \\
\hline Fator 2 (Demanda intermediária) & $(0,034)$ & $(0,036)$ \\
\hline Fator 3 (Demanda final) & $-0,143^{* * *}$ & $-0,091^{* *}$ \\
& $(0,049)$ & $(0,039)$ \\
\hline Dummy para região do Vale do Rio Doce & $-0,084^{* * *}$ & $-0,076^{* *}$ \\
& $(0,033)$ & $(0,031)$ \\
\hline Defasagem espacial (Wy) - Crescimento da produção de leite & $0,974^{* * *}$ & $0,622^{* * *}$ \\
& $(0,123)$ & $(0,206)$ \\
\hline Constante & & $0,532^{* *}$ \\
\hline Teste Anselin-Kelejian - Dependência Espacial & $(0,266)$ \\
\hline Número de observações & $-0,116^{* * *}$ & $-0,083^{* *}$ \\
\hline $\mathbf{R}^{2}$ Espacial & $(0,034)$ & $(0,038)$ \\
\hline
\end{tabular}

${ }^{a}$ As estimativas foram obtidas aplicando IV-GMM. Os instrumentos IV-GMM nos modelos 3 e 4 incluem uso de inseminação artificial; uso de ordenha mecânica; número de estabelecimentos com atividade pecuária que possuem tratores; e proxy para P\&D na atividade pecuária.

b 0 Modelo 3 apresenta a mesma especificação do Modelo 2 apresentado na Tabela 4. A diferença na magnitude dos coeficientes é causada pela estimação usando a rotina econométrica no GeoDaSpace.

${ }^{c}$ Modelo espacial estimado no GeoDaSpace usando matriz de pesos espaciais do tipo distância espacial (matriz de distância com threshold de 130km).

Nota: Erro padrão robusto entre parênteses. Nível de significância: *** $p<0,01,{ }^{* *} p<0,05 e^{*} p<0,1$.

Fonte: Elaborado pelos autores. 
O Modelo 4 na Tabela 5 apresenta os resultados que incluem o controle para a dependência espacial, causada pela heterogeneidade regional do crescimento da produção entre os municípios do Estado. A inclusão da defasagem espacial da variável dependente $(W y)$ no lado direito da equação gerou sensibilidade nos resultados das demais variáveis, embora as principais conclusões obtidas tenham se mantido válidas. Podemos destacar que, após controlarmos os efeitos de endogeneidade espacial causados pelo crescimento dos municípios vizinhos, os resultados que eram atribuídos à produtividade perderam força para explicar o crescimento local. Assim, o seu coeficiente estimado reduziu de 0,195, no Modelo 3 da Tabela 5, para 0,106, no Modelo 4 da Tabela 5.

A defasagem espacial da variável dependente indica que o crescimento da produção de leite é marcado por padrões de localização, captados pelos efeitos da dependência espacial. O coeficiente da variável $W y$, positivo e estaticamente significativo, indica que o crescimento da produção ocorreu de forma concentrada ao longo do território. Logo, o crescimento local da produção de leite é relacionado ao desempenho dos municípios vizinhos. Por conseguinte, podemos confirma a nossa terceira hipótese (H3). Este resultado reforça a importância da conectividade da cadeia produtiva do leite, agindo como força externa para o crescimento da produção nos municípios contíguos.

Portanto, o crescimento local da produção foi impulsionado pela maior capacidade instalada nos próprios municípios e pelo crescimento dos municípios vizinhos. Além disso, o principal mercado consumidor pode estar localizado fora das regiões com maior crescimento de produção, visto que, o coeficiente estimado para a demanda intermediária e final apresentaram efeitos negativos sobre o crescimento local. Em termos de formulação de políticas esse resultado indica a importância do planejamento de canais para escoar a produção, visto que o principal mercado consumidor estaria fora das regiões produtoras. Esse resultado é reforçado pelas tipologias da cadeia do leite (seção 5.2) sugeridas nesse estudo.

\section{Conclusões}

O objetivo desse estudo foi avaliar as dimensões espaciais da cadeia produtiva do leite em Minas Gerais. Com esse propósito desenvolvemos indicadores de potencial latente da atividade leiteira para os 853 municípios de 
Minas Gerais. Avaliamos o potencial de formação de clusters desses municípios, que resultou em uma proposta de tipologia quanto ao seu potencial de acesso ao mercado do leite. E também verificamos como os fatores relacionados à oferta e à demanda dessa cadeia produtiva estão relacionadas ao crescimento local da produção, levando em consideração na modelagem os efeitos de heterogeneidade espacial.

Uma preocupação no nosso exercício empírico diz respeito à possível endogeneidade entre a taxa de crescimento da produção de leite e a variável de produtividade. Essa causalidade tem origem nas diferenças regionais de produtividade, que podem ocorrer nos municípios com maior potencial para aumentar a produção. Por essa razão, depois de fornecermos as estimativas com $\mathrm{MQO}$, verificamos e controlamos essa possível endogeneidade utilizando a técnica de variáveis instrumentais por meio do estimador GMM. Essa abordagem identificou os parâmetros estruturais no modelo de regressão afetados pela endogeneidade e complementou os instrumentos externos com aqueles gerados que não estão correlacionados com os erros heterocedásticos.

Os resultados apontam para a importância das mudanças tecnológicas, refletidas na variável de produtividade, para impulsionar o crescimento da produção. Além disso, também identificamos uma relação negativa entre a demanda intermediária e o crescimento da produção. No entanto, foi possível identificar os efeitos da produtividade e demanda intermediária apenas após o controle do problema de endogeneidade por meio das variáveis instrumentais. Esses resultados são robustos à especificação do modelo que também controla os efeitos de endogeneidade espaciais.

No geral, os resultados encontrados nesse artigo permitem concluir que o crescimento da produção de leite foi maior nos munícipios que já possuem maior capacidade instalada para a produção, identificada na variável de oferta. $\bigcirc$ tamanho da demanda local (intermediaria e final) possui associação negativa e estatisticamente significativa com o crescimento local. Isso permite compreender que o crescimento na produção de leite não foi impulsionado pela demanda local. Ademais, os resultados do tratamento de questões envolvendo transbordamentos espaciais entre os municípios integrantes da cadeia produtiva do leite permitiram conhecer os padrões relacionados à localização produtiva. Desta maneira, identificamos que o crescimento da produção de leite está geograficamente concentrado. 
Consequentemente, os principais resultados desse estudo, a partir do mapeamento e respostas obtidas por meio da construção dos indicadores de potencial latente e da avaliação espacial do mesmo, permitem traçar corredores da atividade leiteira, que podem impulsionar o desenvolvimento econômico e a inserção social dos municípios desses corredores. Além disso, ao tratar espacialmente as informações fornecemos subsídios para que sejam traçadas políticas de atração de investimentos (e.g., empresas processadoras de leite) e discutir políticas de microcrédito ao processo de oferta e de demanda por insumos intermediários.

Cabe ressaltar que, a discussão central do artigo foi a articulação espacial do setor leiteiro em Minas Gerais por meio de uma visão caleidoscópica. Esse direcionamento permitiu evidenciar as heterogeneidades espaciais no que se refere às condições de oferta, demanda e renda no Estado. Assim sendo, acreditamos que a principal contribuição do trabalho está na focalização da dimensão espacial das políticas para o setor a partir do mapeamento aqui realizado.

Ao afirmar isso não estamos negando a existência e a importância de políticas não vinculadas ao território para o setor, ou seja, de políticas generalistas em termos espaciais, tais como a defesa comercial (e.g., políticas para impulsionar exportações), melhoria da infraestrutura (e.g. energia elétrica, internet etc.), programas sanitários, revisão de marcos nos relatórios do setor, créditos de PIS/COFINS para custeio, políticas de apoio à comercialização, construção de fundos para inovação tecnológica, dentre outros. Tais iniciativas são importantes e têm se mostrado eficientes em vários aspectos. Entretanto, ao estudar detidamente as questões espaciais do setor, políticas como melhoria na gestão e na produção, promoção do associativismo, do cooperativismo e da assistência técnica podem ser mais eficazes.

A questão territorial pode ser mais bem entendida a partir das oito tipologias de regiões apresentadas no Quadro 2 do presente trabalho. Esse mapeamento permite, por exemplo, qualificar algumas das iniciativas de órgãos como o Instituto Mineiro de Agropecuária (IMA), a Empresa de Pesquisa Agropecuária de Minas Gerais (EPAMIG), a Empresa de Assistência Técnica e Extensão Rural do Estado de Minas Gerais (EMATER-MG) e a Empresa Brasileira de Pesquisa Agropecuária - Gado de Leite (EMBRAPA - Gado de Leite).

Ao mapear os municípios com base no tamanho de suas propriedades e dos laticínios, como por exemplo, aqueles que têm propriedades e laticí- 
nios de pequeno e médio portes - Grupos 4 e 5 (totalizando 259 municípios) pode ser possível uma ação de intensificação do trabalho de práticas de gestão administrativa e técnica organizados pela EMATER-MG, prioritariamente nesses municípios, como forma de diminuir possíveis disparidades entre esses grupos e o Grupo 3, com municípios com propriedades rurais e laticínios de porte grande. Ademais, tais ações podem não ser necessárias e/ou prioritárias nos Grupos 6, 7 e 8, que congregam 385 municípios mineiros. Em vista disso, a mensagem ao delimitar as questões do setor espacialmente é a busca pela maior eficiência nas ações e, portanto, maior potencial de impulsão do setor.

Na mesma linha descrita anteriormente estão as ações já desenvolvidas pela EPAMIG, por exemplo, que tem algumas ações na área de processamento do leite, que são desenvolvidas no Instituto de Laticínios Cândido Tostes em Juiz de Fora. Consequentemente, a partir do melhor mapeamento das características regionais, ações como melhorias no processamento do leite por meio de divulgação em cartilhas, livros técnicos, palestras podem ter maior efeito se considerado os resultados regionais.

Uma outra lição que podemos tirar dos resultados é a importância das ações ligadas à melhoria da produtividade e, com isto, a construção de uma vantagem comparativa real na produção leiteira no Estado e a importância da formação de clusters de municípios produtores. $O$ conhecimento territorial dessas questões potencializa ações como as desenvolvidas pela EMBRAPA Gado de Leite e pela Universidade Federal de Juiz de Fora (UFJF), por meio do Mestrado Profissional em Ciência e Tecnologia do Leite, quer seja por ações que visam, por exemplo, a utilização de processos químicos para melhor processamento do leite ou até mesmo a distribuição de câmaras de resfriamento regionalizadas. Outra ação de destaque realizada pela Embrapa, em parceria com a iniciativa privada, é o "Desafio de Startups: Ideas for Milk". Em seu segundo ano, este desafio visa estimular a inovação e o empreendedorismo do agronegócio do leite. Para tanto, os participantes devem apresentar projetos tecnológicos que, por meio de aplicativos mobile, soluções de hardwares ou softwares, resolvam problemas da cadeia e maximizem a eficiência de suas atividades

A delimitação territorial das características da cadeia do leite permite evidenciar no espaço questões relativas à cadeia produtiva dividindo, por exemplo, a questão logística em duas partes: da fazenda para a indústria (e.g. treinamento do transportador, logística de captação, condições das 
estradas) e da indústria para o comércio (e.g. logística de entrega e controle de refrigeração). No caso do ciclo fazenda para a indústria uma questão a ser tratada é o treinamento do transportador, que é considerado um elo importante na cadeia produtiva, uma vez que o transporte é determinante na manutenção da qualidade do leite até a indústria. Portanto, ações colegiadas, com a participação de Sindicatos, Cooperativas e órgãos governamentais (EMATER-MG, IMA, EPAMIG), para promover treinamentos, divulgação em cartilhas, e exposições em sites de boas práticas de transporte do leite podem beneficiar diversas regiões, principalmente aquelas localizadas nos Grupos 4 e 5 que são majoritariamente formados por pequenas propriedades.

Ainda dentro do ciclo fazenda-indústria, a delimitação territorial feita nesse trabalho, pode ajudar na implementação de melhores práticas na logística de captação do produto, que ao nosso ver deve permear questões como: a) a formação do banco de dados das propriedades, constando do posicionamento geográfico, tanque de resfriamento: capacidade e marca, avaliação das condições de acesso de veículos e horário das ordenhas, b) avaliação da dispersão geográfica das propriedades e c) manutenção de um sistema de georeferenciamento das estradas rurais. Importante ressaltar que tais procedimentos levariam à racionalização da coleta, o que impactaria positivamente no custo de produção, ou seja, no volume de leite coletado e na quilometragem percorrida na coleta. Tais programas podem ser implementados e adequados de acordo com as tipologias propostas nesse trabalho e, ao nosso ver, podem ser implementados de forma colegiada. Esse tipo de políticas, além de permitir melhorias na captação da produção também podem contribuir para garantir a qualidade do produto. A Rede Brasileira de Laboratórios de Controle de Qualidade de Leite (RBOL) possui dados detalhados sobre a produção de leite, e tais políticas poderiam se beneficiar dos dados de análises já consolidados através dessa Rede.

Um outro ponto relevante do estudo territorial da cadeia do leite realizado nesse artigo se conecta às questões climáticas e aos resultados de produtividade e aumento de produção no estado de Minas Gerais (Ver Figuras $5 \mathrm{~A}$ e $5 \mathrm{~B}$ ): o diferencial de temperatura média entre as regiões mineiras. Como mostram os resultados, a maioria dos principais municípios do Grupo 3 (e.g. Coromandel, Curvelo, Governador Valadares, Montes Claros, Paracatu, Patos de Minas, Teófilo Otoni, Uberaba, Uberlândia, Unaí) se situam em regiões de alta temperatura. Portanto, questões relativas à 
melhoria no manejo, por exemplo, através da ventilação dos estábulos e outros cuidados com a saúde do rebanho, devem ser tratadas também territorialmente afim de manter as condições de bem-estar e de saúde para os animais e, assim, potencializar os ganhos de produtividade. Já existem no mercado soluções de estábulos que minimizam tais problemas, que são os estábulos de ventilação cruzada e outras soluções visando o bem-estar animal. Portanto, há que se considerar, por exemplo, programas que permitam a implementação de tais tecnologias, quer seja por meio de projetos pilotos ou por meio das cooperativas, por exemplo. A ideia é que tal questão seja tratada de forma perene pelos agentes tanto públicos ou privados envolvidos na cadeia do leite.

\section{Referências}

ALMEIDA, E. Econometria espacial. Campinas-SP. Alínea, 2012.

ALMEIDA, E. S.; PEROBELLI, F. S.; FERREIRA, P. G. C. Existe convergência espacial da produtividade agrícola no Brasil?. Revista de Economia e Sociologia Rural, v. 46, n. 1, p. 31-52, 2008.

ANSELIN, L. Spatial Econometrics: Methods and Models, Kluwer Academic, Dordrecht, 1988.

ARAÚJO, N. B; WEDEKIN, I; PINAZZA, L. Complexo agroindustrial: o Agribusiness Brasileiro. São Paulo: Agroceres, 1990.

ARAÚJO, B. C.; CAVALCANTE, L. R.; ALVES, P. Variáveis proxy para os gastos empresariais em inovação com base no pessoal ocupado técnico-científico disponível na Relação Anual de Informações Sociais (RAIS). Instituto de Pesquisa Econômica Aplicada (IPEA). Randar: Tecnologia, Produção e Comércio Exterior, n. 5, p. 16-21, 2009.

AZEVEDO, P. F. de. Concorrência no Agribusiness. In: ZYLBERSZTAJN, D.; NEVES, M. F. (Org.) Economia e Gestão dos Negócios Agroalimentares. São Paulo: Pioneira, 2000.

BATALHA, M. Gestão Agroindustrial. São Paulo: Atlas, 1997.

BAUM, C.; SCHAFFER, M.; STILLMAN, S. Enhanced routines for instrumental variables/ generalized method of moments estimation and testing. Stata Journal, v. 7, n. 4, p. 465506, 2007.

BORGES, M. S.; CASTRO, M. C. D.; GUEDES, C. A. M; ALIMONDA, H. A. Modernização, Trabalho e Produtividade na Pequena Produção Leiteira na Argentina e no Brasil. Revista ADM.MADE, v. 18, n. 1, p. 12-31, 2014.

CAMERON, A. C.; TRIVEDI, P. K. Microeconomics: methods and applications. Cambridge University Press, Cambridge, 2005.

CAMPOS, S. A. C., PEREIRA, M. W. G.; TEIXEIRA, E. C. Trajetória de modernização da agropecuária mineira no período de 1996 a 2006. Economia Aplicada, v. 18, n. 4, p. 717-739, 2014.

CASTRO, A. M. G. de. Prospecção de cadeias produtivas e gestão da informação. Transinfor- 
mação, v. 13, n. 2, p. 55-72, 2001.

CASTRO, L. S.; LIMA, J. E. A soja e o estado do Mato Grosso: existe alguma relação entre o plantio da cultura e o desenvolvimento dos municípios? Revista Brasileira de Estudos Regionais e Urbanos, v. 10, n. 2, p. 177-198, 2016.

DAVIS, J. H.; GOLDEBERG, R. A. Concept of Agribusiness. Boston: Harvard University, 1957.

EMBRAPA. Empresa Brasileira de Pesquisa Agropecuária. Produção de Leite no Sudeste do Brasil. Sistemas de produção de leite para diferentes regiões do Brasil. Embrapa Gado de Leite - Sistema de Produção, n. 4. Brasília, 2011.

EVERITT, B. Cluster Analysis. London: Heinemann Educational Books, 1977.

FAO - Food and Agriculture Organization of the United Nations. Statistics, 2017. Disponível em: <http://www.fao.org/faostat/en/\#data>. Acesso em: 21/10/2017.

FBB - Fundação Banco do Brasil. Desenvolvimento Regional Sustentável: Bovinocultura de Leite, volume 1. Brasília: Banco do Brasil, 2010.

GOMES, A. T.; LEITE, J. L. B. O relacionamento na cadeia agroindustrial do leite para os novos tempos. In: GOMES, A. T.; LEITE, J. L. B.; CARNEIRO, A. V. I. (Org.) O agronegócio do leite no Brasil. Juiz de Fora: Embrapa Gado de Leite. 2001, p. 139-154.

HAIR Jr., J. F.; BLACK, W. C.; BABIN, B. J.; ANDERSON, R. E.; TATHAM, R. L. Análise multivariada de dados. $5^{\mathrm{a}}$ ed. Porto Alegre: Bookman, 2005.

HUNT, D., SHIKI, S., RIBEIRO, R., BIASI, D.; FARIA, A. P. Comparação de indicadores de desempenho de produtores de leite localizados dentro e fora de assentamentos de reforma agrária no Triângulo Mineiro. Revista de Economia e Sociologia Rural, v. 47, n. 1, p. 211-248, 2009.

IDEAS FOR MILK. Desafio de Startups, 2017. Disponível em: <http://www.ideasformilk.com. br/desafio-startups/conteudo/inicio $>$. Acesso em: 31/10/22017.

JOHNSON, R.; WICHERN, D. Applied Multivariate Statistical Analysis. $5^{\text {a }}$. ed. Englewood Clifs: Prentice-Hall, 2002.

LEMOS, M. B., GALINARI, R., CAMPOS, B., BIASI, E.; SANTOS, F. Tecnologia, especialização regional e produtividade: um estudo da pecuária leiteira em Minas Gerais. Revista de Economia e Sociologia Rural, v. 41, n. 3, p. 117-138, 2003.

LOPES, P. F., REIS, R. P.; YAMAGUCHI, L. C. T. Custos e escala de produção na pecuária leiteira: estudo nos principais estados produtores do Brasil. Revista de Economia e Sociologia Rural, v. 45, n. 3, p. 567-590, 2007.

KAGEYAMA, A.; LEONE, E. Trajetória da modernização e emprego agrícola no brasil, 1985 - 1996. Revista de Economia e Sociologia Rural, v. 40, n. 1, p. 9-28, 2002.

KELEJIAN, H. H.; PRUCHA, I. R. A generalized spatial two-stage least squares procedure for estimating a spatial autoregressive model with autoregressive disturbances. Journal of Real Estate Finance and Economics, v. 17, n. 1, p. 99-121, 1998.

KELEJIAN, H. H.; PRUCHA, I. R. Estimation of simultaneous systems of spatially interrelated cross sectional equations. Journal of Econometrics, v. 118, n. 1, p. 27-50, 2004.

KELEJIAN, H. H.; PRUCHA, I. R. Specification and estimation of spatial autoregressive models with autoregressive and heteroskedastic disturbances. Journal of Econometrics, v. 157, n. 1, p. 53-67, 2010. 
MARTINS, P.C.; GUILHOTO, J.J.M. Leite e derivados e a geração de emprego, renda e ICMS no contexto da economia brasileira. In: GOMES, A. T.; LEITE, J. L. B.; CARNEIRO, A. V. (Org.) O agronegócio do leite no Brasil. Brasília: Embrapa Gado de Leite, 2001.

MELO, C. O.; PARRÉ, J. L. Índice de desenvolvimento rural dos municípios paranaenses: determinantes e hierarquização. Revista de Economia e Sociologia Rural, v. 45, n. 2, p. 329365, 2007.

MINGOTI, S. A. Análise de dados através de método de estatística multivariada: uma abordagem aplicada. Belo Horizonte: Editora UFMG, 2007.

MONTOYA, M. A.; FINAMORE, E. B. Delimitação e encadeamentos de sistemas agroindustriais: o caso do complexo lácteo do Rio Grande do Sul. Economia Aplicada, v. 9, n. 4, p. 663$682,2005$.

MEYER, L. Modernização da agricultura e desenvolvimento sustentado: o caso de Minas Gerais 1970 a 1985. 1997. Dissertação (Mestrado em Economia Aplicada) - Universidade Federal de Viçosa, Departamento de Economia Rural, Programa de Pós-Graduação em Economia Aplicada, Viçosa, 1997.

MEYER, L.; BRAGA, M. O crescimento das desigualdades tecnológicas na agricultura mineira. Revista de Economia e Sociologia Rural, v. 36, n. 2, p. 59-90, 1998.

PEROBELLI, F. S.; ALMEIDA, E.; ALVIM, M. I. S.; FERREIRA, P. G. C. Produtividade do setor agrícola brasileiro (1991-2003): uma análise espacial. Nova economia, v. 17, n. 1, p. 65-91, 2007.

PEROBELLI, F. S.; OLIVEIRA, A. F.; NOVY, L. G. G.; FERREIRA, M. V. Planejamento regional e potenciais de desenvolvimento dos municípios de Minas Gerais na região em torno de Juiz de Fora: uma aplicação de análise fatorial. Nova Economia, Belo Horizonte, v. 9, n.1, p. 121-150, 1999.

SANTOS, M. A. S.; SANTANA, A. C.; RAIOL, L. C. B.; LOURENÇO, J. B. Fatores Tecnológicos da Pecuária Leiteira no Estado do Tocantins. Revista em Agronegócios e Meio Ambiente, v. 7, n. 3, p. 591-612, 2014.

SILVA, J. G. Complexos agroindustriais e outros complexos. Revista da Associação Brasileira Reforma Agrária, v. 21, n. 3, p. 5-34, 1991.

SIQUEIRA, K. B.; KILMER, R. L.; CAMPOS, A. C. The dynamics of farm milk price formation in Brazil. Revista de Economia e Sociologia Rural, vol. 48, n. 1, pp. 41-61, 2010.

SOUZA, P. M.; LIMA, J. E. Intensidade e dinâmica da modernização agrícola no Brasil e nas unidades da Federação. Revista Brasileira de Economia, v. 57, n. 4, p. 795-824, 2003.

VIANA, G.; FERRAS, R. P. R. A cadeia produtiva do leite: um estudo sobre a organização da cadeia e sua importância para o desenvolvimento regional. Revista Capital Científico, v. 5, n. 1, p. 23-40, 2007.

VILELA, D.; RESENDE, J. C. D.; LEITE, J. B.; ALVES, E. A evolução do leite no Brasil em cinco décadas. Revista de Política Agrícola, v. 26, n. 1, p. 5-24, 2017.

\section{Sobre os autores}

Fernando Salgueiro Perobelli - fernando.perobelli@ufjf.edu.br

Departamento de Economia, Laboratório de Análises Territoriais e Setoriais, Universidade Federal de Juiz de Fora. 
Inácio Fernandes de Araújo Junior - inaciofaj@gmail.com

Departamento de Economia, Laboratório de Análises Territoriais e Setoriais, Universidade Federal de Juiz de Fora.

Lucas Siqueira de Castro - lucancastro@hotmail.com

Departamento de Economia, Universidade Federal Rural do Rio de Janeiro.

\section{Sobre 0 artigo}

Recebido em 07 de abril de 2017. Aprovado em 22 de novembro de 2017. 